\title{
Stable Mineral Recrystallization in Low Temperature Aqueous Systems: A Critical Review
}

\author{
Christopher A. Gorski1 ${ }^{1, *}$ and Matthew S. Fantle ${ }^{2}$
}

\begin{abstract}
Minerals may undergo recrystallization reactions in low temperature $\left(<100^{\circ} \mathrm{C}\right)$ aqueous systems, during which they exchange isotopes and trace elements with the dissolved reservoir without undergoing overt structural or morphological changes. These interfacial reactions, which are often referred to in the literature as "atom exchange" and herein as "stable mineral recrystallization", have important implications for the use of isotopic and elemental proxies to interpret past temperatures, oxidation states, and aqueous chemistries on Earth. The reactions are also significant for modern environments, including engineered systems, as they imply that mineral lattices may be substantially more open to exchanging toxic elements and radionuclides with coexisting solutions than previously thought. To date, observations of stable mineral recrystallization are distributed among several disciplines, and no work has attempted to review their findings comprehensively. Accordingly, this review article presents laboratory evidence for stable mineral recrystallization, describes data collection and interpretation strategies, summarizes similar recrystallization systematics observed in multiple studies, explores the potential occurrence of stable mineral recrystallization in natural systems, and discusses possible mechanisms by which stable mineral recrystallization occurs. The review
\end{abstract}


focuses primarily on carbonates, sulfates, and iron oxides because these minerals have been studied most extensively to date. The review concludes by presenting key questions that should be addressed in this field to further understand and account for stable mineral recrystallization in natural and engineered aqueous systems at low temperatures.

\section{INTRODUCTION}

Minerals are fundamentally important to the fields of geoscience and environmental geochemistry. A mineral's elemental and isotopic compositions are often viewed as reflecting the physical and/or geochemical conditions under which it formed. Accordingly, minerals such as carbonates serve as important geochemical proxy archives that are used to constrain temperatures, oxidation states, and aqueous chemistries (e.g., seawater chemical evolution) in a range of past environments. In modern environments, minerals can dictate the bioavailabilities of biological nutrients and inorganic environmental contaminants through sorption, coprecipitation, and structural incorporation reactions (e.g., Cooper et al., 2000; Cooper et al., 2005). Consequently, minerals are used to prevent and mitigate groundwater contamination by immobilizing toxic or radioactive elements. A classic case of using minerals to prevent groundwater contamination is the employment of barite $\left(\mathrm{BaSO}_{4}\right)$ in radioactive waste repositories to immobilize radium $(\mathrm{Ra})$ through the formation of a solid solution $\left(\mathrm{Ra} \times \mathrm{Ba}_{1-\mathrm{SO}} \mathrm{SO}_{4}\right)$, which is substantially less soluble than $\mathrm{RaSO}_{4}$ (Bosbach et al., 2010; Curti et al., 2010; Klinkenberg et al., 2014; Brandt et al., 2015).

The effective use of minerals in both fields requires an understanding of how a mineral's elemental or isotopic composition changes over time. A mineral that preserves its original composition over long time scales is characterized as a "high fidelity" proxy archive; in contrast, "low fidelity" proxy archives are those that have been altered to a significant extent due to postformational processes. Because low fidelity archives reflect the conditions in a multitude of environments, interpreting isotopic and/or elemental compositions in terms of formational environment can result in incorrect conclusions regarding paleoclimate and paleoenvironment. Likewise, a mineral with low fidelity is relatively ineffective at permanently immobilizing toxic and radioactive elements. 
In general, the post-formational changes that alter a mineral's elemental and isotopic compositions in the environment occur in the presence of water (Putnis, 2009; Prieto et al., 2013; Putnis, 2014). Solid-state diffusion of elements within a mineral is generally reasoned to be too slow to be important in low temperature systems $\left(\mathrm{T}<100^{\circ} \mathrm{C}\right)$, even over geological time scales (e.g., Urey, 1948; Fisler and Cygan, 1999; Cole and Chakraborty, 2001). Instead, low temperature mineral transformations are thought to occur primarily by dissolution and precipitation reactions (e.g., Cole and Chakraborty, 2001; Putnis, 2009). These reactions can involve a mineral transforming from one phase to another or a mineral maintaining its structure but reforming into more stable particles through aggregation and growth (e.g., Ostwald ripening), which can lead to element- or nuclide-specific repartitioning between the aqueous and solid phases. While there are many different mineral growth and transformation mechanisms that can cause these changes, they are generally thought to share a commonly agreed upon feature: alterations to a mineral's elemental and/or isotopic compositions should be accompanied by structural and/or morphological changes (Putnis, 2009; Yardley, 2009; Putnis and John, 2010; Putnis and RuizAgudo, 2013).

In recent years, however, this notion has been challenged. Evidence collected in laboratory studies have shown that a mineral's elemental and/or isotopic composition can be significantly altered in low-temperature aqueous environments at rapid rates in the absence of overt structural or morphological changes. Using isotopic or elemental tracers, researchers found that extensive isotopic exchange occurs between mineral and aqueous ions over experimental time scales - without any overt changes in the mineral structure or grain size that exceed rates expected for solid-state diffusion (Stipp et al., 1992; Handler et al., 2009; Curti et al., 2010; Frierdich and Catalano, 2012a; Avrahamov et al., 2013; Lestini et al., 2013; Handler et al., 2014). In many cases, investigations have concluded that the mineral has undergone complete exchange with the aqueous solution, as evidenced by the solid and solution having virtually identical isotopic compositions at the end of the experiment (Zachara et al., 1991; Handler et al., 2009; Bosbach et al., 2010; Avrahamov et al., 2013; Handler et al., 2014; Joshi and Gorski, 2016). This suggests that atoms initially deep within the bulk mineral lattice are capable of exchanging with atoms in solution. The effect that these reactions can have on the isotopic 
and elemental compositions of minerals can be profound, particularly when the aqueous concentration of the element of interest is sizeable compared to the concentration in the solid phase (i.e., the leverage to alter the solid is significant; see (Fantle and Higgins, 2014) for more detail).

Translating the observations of this phenomenon from laboratory studies to natural systems is not straightforward. Analyses of minerals and their surrounding pore fluids collected from field sites indicate that materials such as deep sea sediments and carbonates undergo significant post-depositional isotopic and elemental exchange with pore fluids at low temperatures (Killingley, 1983; Mozeto et al., 1984; Richter and DePaolo, 1987; Spivack and Edmond, 1987; Schrag et al., 1992; Richter and Liang, 1993; Schrag et al., 1995; Fantle and DePaolo, 2007; Jones et al., 2009; Fantle et al., 2010; Wu et al., 2011; Avrahamov et al., 2013; Fantle, 2015). Determining the extent to which this post-depositional exchange is coupled to structural and/or morphological changes in the mineral is obviously challenging, however, since the system is open and the original specimen is not well characterized. Regardless of these complications, simply recognizing that a mineral may undergo significant compositional changes without overt accompanying morphological alterations has important implications for how data from natural samples is interpreted. For instance, the primary method for recognizing post-depositional alteration in biogenic calcium carbonate is visual evidence for morphological changes (e.g., test fragmentation, micro- and ultrastructural alteration, and/or assemblage change) or the presence of secondary mineralization products (e.g., micritic cements and euhedral calcite). Clearly, the exchange reactions typically associated with the process described here would be difficult to identify using such indicators, leading to potentially erroneous conclusions regarding the interpreted conditions under which a mineral formed.

\subsection{INTRODUCTION TO KEY TERMINOLOGY}

In the literature, interfacial exchange reactions between a mineral and aqueous ions have been described using various terminologies: isotope exchange, atom exchange, recrystallization, and neomorphism (e.g., Nakamura et al., 2005; Pedersen et al., 2005; Poulson, 2005; Sexton et al., 2006; Handler et al., 2009; Handler et al., 2014). Both isotope exchange and atom exchange have 
been used to describe the exchange of atoms between two components in a given system. The distinction between these two terms is that isotope exchange refers only to two atoms of the same element exchanging (e.g., aqueous $\mathrm{Ba}^{2+}$ exchanging with structural $\mathrm{Ba}^{2+}$ in $\mathrm{BaSO}_{4}$ ), while atom exchange includes isotope exchange as well as elemental substitution reactions (e.g., the replacement of structural $\mathrm{Ba}^{2+}$ by aqueous $\mathrm{Ra}^{2+}$ in $\mathrm{BaSO}_{4}$ ). While the terms "isotope exchange" and "atom exchange" accurately describe the phenomenon discussed in this review, the usage of these terms is not unique to this phenomenon. For example, both terms have been used to characterize exchange between components of a single phase (e.g., exchange between two aqueous complexes) (Cole and Chakraborty, 2001). Additionally, when such exchange reactions involve a mineral phase, these terms cannot be used to differentiate between exchange coupled to a mineral transformation and exchange that occurs in the absence of a mineral transformation.

The term recrystallization has been defined in different ways over time, due in part to the term being used by multiple sub-disciplines within the geosciences and metallurgy (e.g., Folk, 1965; Spry, 1969; Yund et al., 1991). Recrystallization was first defined by Sorby (1880) as the reorganization of a mineral or metallic constituent already present in a system. This definition includes the phenomenon of interest in this review, but also includes other processes, such as mineral replacement reactions, secondary mineralization transformations, and atom exchange reactions coupled to structural and/or morphological changes in the mineral. In the geosciences, recrystallization was later defined more narrowly to refer to processes in which the mineral structure "remains identical" through a reaction (Folk, 1965; Spry, 1969; Bathurst, 1975). This definition included processes that were coupled to changes in the mineral morphology and/or trace element compositions (e.g., the recrystallization of a calcite with a high $\mathrm{Mg}$ content to a calcite with a low Mg content). More recently, recrystallization has been used to describe (1) the growth of new grains of a mineral with the same composition (Yund et al., 1991) and (2) the growth of new mineral phases through dissolution and precipitation reactions (Yund et al., 1991; Putnis, 2009). With specific reference to carbonate diagenesis, the term "recrystallization" has been denoted as a catch-all term that encompasses "all forms of diagenetic alteration of biogenic calcite“, mainly due to its less strictly defined usage in the literature (Sexton et al., 
2006). From these studies, it is apparent that the term recrystallization could be used to describe the phenomenon of interest in this review, but the term would be too general and may be misinterpreted and/or misunderstood.

The term "neomorphism" faces the same issue of inconsistent usage as the term recrystallization. Neomorphism was recently used to describe the replacement of biogenic calcite by so-called inorganic calcite (i.e., replacement accompanied only by a change in crystal "form") (Sexton et al., 2006), consistent with the phenomenon of interest in this review. However, Folk (1965) used the term to describe diagenetic mineral transformations of various types, including recrystallization and inversion. In fact, Folk (1965) described "neomorphism" as a "comprehensive term of ignorance (pg. 21)" that refers to "all transformations between one mineral and itself or a polymorph" no matter if the affected crystals change in size and/or shape. Consequently, the use of neomorphism to describe this phenomenon could also lead to confusion or misinterpretation.

Given both the ambiguities in current usage and the original definitions of the terms "recrystallization" and "neomorphism" in the sedimentary diagenesis literature (e.g., Folk, 1965; Bathurst, 1975), we suggest the term "stable mineral recrystallization" to describe the phenomenon emphasized in this review. We define stable mineral recrystallization as a reaction in which a "stable mineral" extensively exchanges atoms with ions in solution under apparent chemical equilibrium conditions without the occurrence of overt changes to the mineral structural, morphology, or grain size. In this case, "extensively exchanges" means that the number of atoms participating in mineral-fluid exchange exceeds the number of atoms initially present at the mineral-fluid interface. The term "overt" refers generally to those changes that are observable at the macroscopic or microscopic level. This term is more of a loose descriptor than a solid constraint, as the description of a change as overt depends heavily on the spatial scale of the observation. Thus, this term does not necessarily refer to changes that may be detectable in the future using techniques with high spatial resolutions, such as transmission electron and/or atomic force microscopy.

In this definition, a "stable mineral" is the most thermodynamically stable, and therefore least soluble, solid polymorph for a given chemical composition at ambient conditions (i.e., 
temperature, pressure, and solution composition). For example, calcite $\left(\mathrm{CaCO}_{3}\right)$ is considered a "stable mineral" under most environmental conditions because it is the least soluble solid that contains $\mathrm{Ca}^{2+}$ and $\mathrm{CO}_{3}{ }^{2-}$ (Tai and Chen, 1998). Aragonite, a $\mathrm{CaCO}_{3(\mathrm{~s})}$ polymorph, is more soluble than calcite under most environmentally relevant conditions (Morse et al., 1980; Plummer and Busenberg, 1982; Mucci, 1983), and therefore would not be considered a "stable mineral", as it is expected to transform to calcite in aqueous systems (Bischoff and Fyfe, 1968; Budd, 1988; Putnis, 2009). Of course, such "stable minerals" can exist in a range of forms that have varying surface energies and imperfections (e.g., heterogeneities, crystal defects, and elemental impurities) that influence their solubilities and hence thermodynamic stabilities (Fyfe and Bischoff, 1965; Nordstrom et al., 1990; Navrotsky et al., 2008). These deviations from ideality will affect local surface energies of the mineral and likely if and how a mineral recrystallizes. For the purpose of this review, we focus on low temperature $\left(\mathrm{T}<100^{\circ} \mathrm{C}\right)$ aqueous systems, but note that stable mineral recrystallization could and may occur at higher temperatures.

\subsection{OUTLINE OF THE REVIEW}

Observations of low-temperature stable mineral recrystallization are spread among several fields and - to the best of our knowledge - have not been discussed collectively to date. Therefore, the purpose of this review article is to summarize and evaluate critically the observations of stable mineral recrystallization from laboratory experiments and discuss the commonalities and differences among previous reports. Accordingly, we discuss the roles of mineralogy, solution conditions, and trace elemental chemistry of minerals on the observations of stable mineral recrystallization. In the review, we focus on data collected for sulfates, carbonates, and iron oxides, as these minerals have been the most extensively studied to date.

The review of existing work is divided into two sections. The first section focuses on laboratory-based studies, in which stable isotopes, radioactive nuclides, and/or trace elements are used as probes of stable mineral recrystallization over short time scales. We focus our discussion on studies in which evidence indicates that minerals extensively recrystallized, but exhibited no overt structural changes over the course of the reaction. The second section focuses on field-based studies, in which the spatial distribution of isotopes and/or trace elements in 
marine sediments clearly indicate post-depositional exchange between the bulk solid and coexisting pore fluids over long time scales. For the field-based examples discussed, we explore where in the surface Earth system stable mineral recrystallization may be relevant and question if the reaction observed in marine carbonates could be due in part to a long-term expression of stable mineral recrystallization, as observed over short time scales in the laboratory.

To these ends, we first discuss how stable mineral recrystallization data has been interpreted in the literature. Multiple models have been developed to quantify rates and extents, and each can yield substantially different results with respect to the extent of mineral exchange, depending on the relative pool sizes of the aqueous and mineral phases. We then summarize the available data from laboratory and field studies and, using these data, address the possible mechanism(s) of stable mineral recrystallization. We conclude by presenting outstanding questions whose answers are required to further our understanding of stable mineral recrystallization.

\section{Laboratory ObSERVATIONS OF Stable Mineral Recrystallization}

\subsection{Summary of experimental data collection protocol and data interpretation}

In laboratory studies, stable mineral recrystallization is most commonly examined by exposing a mineral to an aqueous solution that is ostensibly saturated with respect to the mineral phase. To generate an initial isotopic disequilibrium between the mineral and the solution, the solution or mineral is enriched with either a stable or radioactive isotope tracer of the target element. Both stable and radioactive isotope tracers are highly attractive in that small amounts of tracer can be added to solution quite easily without disturbing chemical equilibrium, but each have unique benefits and limitations. Stable isotopes are advantageous in that they are not radioactive, they are readily available commercially, and isotope ratios can be quantified with high analytical precision. In cases where the three-isotope approach is taken, the data collected can also be used to determine equilibrium isotopic fractionation factors (e.g., Guilbaud et al., 2011; Frierdich et al., 2014b), which are important for interpreting the isotopic composition of the rock record. Potential downsides of working with stable isotopes are that 
measurements on isotope ratio mass spectrometers can be expensive and sample purification using ion exchange chromatography is often time and labor intensive. In contrast, the analysis of radioactive isotope tracers only requires a simple detector devise (e.g., a liquid scintillation counter), which can make several measurements per hour, and is therefore inexpensive and rapid. Radioactive tracers can also frequently be used at lower concentrations than stable isotope tracers, depending on the specific nuclide's half-life and counting efficiency. The major downsides of working with radioactive isotopes are their radiotoxicities, the need to account for decay over time, and additional safety precautions that must be taken for handling, storage, and transportation of radionuclides.

After the mineral is placed in solution, the amount of tracer in the solid and/or aqueous phases is measured over time (e.g., tens to hundreds of days) to track stable mineral recrystallization. In some cases, parallel reactors are utilized so that whole reactors can be sacrificed at once to characterize both the solid and fluid phases, which can be critical to accounting for possible tracer losses in the experimental system and to evaluate the degree to which the system is closed (i.e., that all tracer can be accounted for in the fluid and solid phases). Isotopic analyses are often combined with spectroscopic measurements and microscopic imaging of the solid phase to determine if (and how) the mineral changed over the course of the experiment. For the purpose of this review, we focus on studies in which such mineralogical characterizations were done in the study (or in previous studies examining similar minerals and experimental conditions) to avoid instances in which a mineral transformation may have occurred.

The chemical reaction describing stable mineral recrystallization from the perspective of cationic isotopic exchange is:

$$
{ }^{k} A_{(a q)}^{n+}+{ }^{j} A B_{(s)} \leftrightarrow{ }^{j} A_{(a q)}^{n+}+{ }^{k} A B_{(s)}
$$

where $A$ is the element undergoing exchange, ${ }^{k} A$ and ${ }^{i} A$ refer to specific isotopes of element $A, n$ refers to the ionic charge of aqueous species $A$ in the fluid, $B$ is a counter ion in the mineral lattice (the stoichiometry of $A B$ will depend on the charge of $B$ relative to $A$ ), $s$ denotes the solid phase, and aq denotes the aqueous species in the fluid phase $(f)$. In this review, we assign $k$ as the index for the radioactive nuclide, and $i$ and $j$ as the indices for two stable nuclides. 

radioactive or stable isotope tracers because the two approaches utilize different notations. In radioactive tracer studies, the mass or moles of the tracer in each phase is typically reported. Assuming the radioactive tracer experiment is a closed system, the rate of change of the mass of radiotracer in the fluid phase is:

$$
\begin{gathered}
\frac{d N^{k} A_{(a q)}}{d t}={ }^{k} F_{\text {diss }}-{ }^{k} F_{\text {precip }}-\lambda N^{k} A_{(a q)} \\
\frac{d N^{k} A_{(a q)}}{d t}=F_{\text {diss }}^{\text {bulk }} \frac{N^{k} A_{(s)}}{N_{A_{(s)}}}-F_{\text {precip }}^{\text {bulk }} \frac{N^{{ }^{k} A_{(a q)}}}{N_{A_{(a q)}}}-\lambda N{ }^{k} A_{(a q)}
\end{gathered}
$$

where ${ }^{k} F_{i}$ is the flux of ${ }^{k} A$ due to dissolution or precipitation (in units of moles per time), $\lambda$ is the decay constant of the radioactive nuclide (units of time ${ }^{-1}$ ), $N^{k} A_{(i)}$ is the moles of the radioactive tracer ${ }^{k} A_{(a q)}$ in phase $i$, and $t$ is time. The fluxes can be parameterized further by including reaction rate terms (such as for the bulk solid; i.e., Eq. $2 \mathrm{~b}$ ), fractionation factors, and/or partition coefficients. What Eq. 2a demonstrates quite simply is that if the decay term is neglected (or corrected for), then the concentration of $A_{(a q)}$ is a function of the dissolution and precipitation fluxes. If recast in terms of the bulk solid (Eq. 2b), it is also clear that even in a recrystallizing system $\left(F_{\text {diss }}^{b u l k}=F_{\text {precip }}^{b u l k}\right)$, the fluid will evolve if the mass ratios of the radiotracer to total element are not the same in the fluid and solid. So-called "complete" exchange is deemed to have occurred when the solid and solution have reached isotopic equilibrium (i.e., when the fluid and solid have the same isotopic compositions plus or minus mass-dependent isotopic effects); such an equality does not mean exchange ceases, only that it is no longer detectable using the tracer.

Stable isotope tracer studies report isotopic compositions using delta notation, which describes the isotopic ratio $\left(N_{i_{A}} / N_{j_{A}}\right)$ of a given sample relative to an internationally accepted standard:

$$
\delta^{i / j} A(\text { permil, \%o })=\left(\frac{\left(\frac{N i_{A}}{N_{j}}\right)_{\text {sample }}}{\left(\frac{N_{A}}{N_{i}}\right)_{A}}-1\right) \cdot 1000
$$


where ${ }^{i} A$ and ${ }^{i} A$ are isotopes of $A$ with nuclidic masses $i$ and $j$, respectively. The change in the delta value of the aqueous phase over time is:

$$
\frac{d \delta^{i / j} A_{(a q)}}{d t}=\frac{F_{\text {diss }}^{\text {bulk }}}{N_{A_{(a q)}}}\left(\delta^{i / j} A_{d i s s} s^{i / j} A_{(a q)}\right)-\frac{F_{\text {precip }}^{\text {bulk }}}{N_{A_{(a q)}}} \Delta^{i / j} A_{s-a q}
$$

where $N_{A}$ is the mass of $A$ in the aqueous phase, $\delta^{i / j} A_{(a q)}$ is the isotopic composition of $A$ in the fluid, $\delta^{i / j} A_{i}$ is the isotopic composition of the $i^{\text {th }}$ flux $\left(F_{i}\right), F_{i} / N_{A}$ is $1 / \tau_{\mathrm{i}}$ (where $\tau_{\mathrm{i}}$ is the response time of the $i^{\text {th }}$ flux), and $\Delta^{i / j} A_{s-f}$ is the fractionation factor (in units of permil, \%o) associated with mineral precipitation. No isotopic fractionation is assumed to occur during dissolution; such an isotope effect could be accounted for by making the substitution $\delta^{i / j} A_{d i s s}=\delta^{i / j} A_{s}-\Delta^{i / j} A_{s-a q}$. If the precipitation flux is ignored or the fractionation factor is relatively small, then the rate at which the fluid $\delta$ changes is primarily a function of the dissolution flux (i.e., the rate of reaction) relative to the size of the fluid reservoir (i.e., $1 / \tau_{\mathrm{i}}$ ), and the extent of isotopic disequilibrium (i.e., $\left.\delta^{i / j} A_{\text {diss }}-\delta^{i / j} A_{(a q)}\right)$.

When considering either stable or radioactive isotope tracers, the interpreted rate and extent of change depends not only on the solid and aqueous $\delta^{i / j} A$ or ${ }^{k} A$ values, but also on the initial isotopic disequilibrium between the phases:

$$
F_{\text {diss }}^{\text {bulk }}=F_{\text {precip }}^{\text {bulk }}=\frac{\frac{d \delta^{i / j} A_{(a q)}}{d t} \cdot N_{A_{(a q)}}}{\left(\delta^{i / j} A_{\text {diss }} \delta^{i / j} A_{(a q)}\right)}
$$

For a dissolution flux written in terms of \% solid reacted per unit time ( $R$ : mass reacted per unit mass per unit time):

$$
R=\frac{\frac{d \delta^{i / j} A_{(a q)}}{d t} .}{\left(\delta^{i / j} A_{d i s s^{i / j}} \delta_{(a q)}\right)} \cdot\left(\frac{N_{A_{(a q)}}}{N_{A_{(s)}}}\right)
$$

This expression highlights the dependence of the interpreted rate on the solid to fluid mass ratio. An important consequence of this dependence is that changes in $\delta^{i / j} A$ or ${ }^{k} A / N_{A}$ (depending on how the data are presented) in the solid or fluid phases cannot be used to infer reaction kinetics directly and should not be used to compare data from multiple experiments in which the solid:fluid mass ratios differ. Accordingly, in experiments with high solid:fluid mass ratios $(>1)$, the fluid will be a more sensitive indicator of temporal variability than the solid phase. When the solid:fluid mass ratio is low $(<1)$, the solid is the more sensitive indicator. As a result, 
two otherwise identical experiments having different solid:fluid will yield different temporal trends in $\delta^{i / j} A$ or ${ }^{k} A / N_{A}$ that depend on the solid:fluid mass ratio. The importance of the solid:fluid mass ratio is highlighted for a simple system in which unreacted, initial solid dissolves at a constant \% per time and re-precipitates as an exchanged solid (Figure 1). In this example, it can clearly be seen that solid:fluid mass ratio has a large effect on the rate at which the system approaches the assumed "equilibrium" condition (i.e., $\delta^{i / j} A_{(a q)}-\delta^{i / j} A_{(s)}=0$ ). Interpretations of experimental data, therefore, must account for solid:fluid mass ratio.

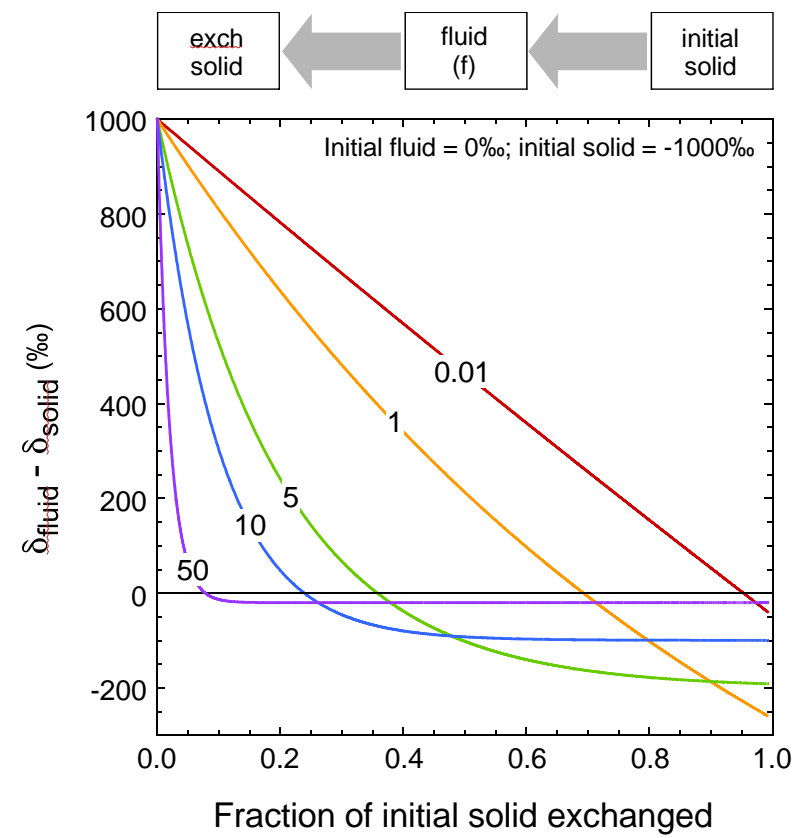

Figure 1. Time-dependent numerical box model simulation of stable mineral recrystallization for a generic system in which unreacted solid with no initial tracer $\left(\delta_{\text {solid,initial }}=-1000 \%\right.$, where delta values are calculated by normalizing the tracer/major nuclide ratio to the initial fluid ratio) dissolves and reprecipitates over time, exchanging with a fluid that initially contains all of the isotopic tracer $\left(\delta_{\text {fluid,initial }}=\right.$ $0 \%$ ). The delta notation ( $\delta_{\text {fluid }}$ or $\delta_{\text {solid }}$ ) refers to the isotopic composition of the fluid and bulk solid, respectively, relative to the initial fluid. The various curves reflect simulations in which the exchange rate (parameterized as \% reacted/time) is identical, and only the solid:fluid mass ratio differs. The numerical label on each curve indicates the solid:fluid mass ratio in each simulated scenario.

Even when the solid:fluid mass ratio and the mean isotopic compositions of the solid and fluid phases are known at some point in time, there is still insufficient information to calculate the rate or extent of recrystallization (e.g., Curti et al., 2010; Handler et al., 2014). This can be illustrated by examining a case in which only a fraction of the solid has recrystallized. The solid would have two reservoirs with different isotopic compositions: the fraction of the solid that has not recrystallized (which has the same isotopic composition as that of the initial, 
homogeneous solid) and the fraction of the solid that has recrystallized (which has an isotopic composition that differs from that of the initial solid because of the large extent of isotopic disequilibrium between solid and fluid). Calculating the relative sizes of these fractions using a mass balance approach requires knowledge of the isotopic composition of the recrystallized solid. This isotopic composition cannot be known a priori, as it depends on how much the recrystallized fraction continues to react with the solution after the initial exchange event (Criss et al., 1987; Dubinina and Lakshtanov, 1997; Cole and Chakraborty, 2001). Measuring this value directly is analytical challenging. Consequently, the isotopic composition of the recrystallized fraction is frequently assumed in order to calculate the fraction of the solid that has recrystallized at a given time point.

Three distinct models have been developed to constrain extents of recrystallization, each of which assumes a different isotopic composition in the recrystallized fraction of the solid: the homogeneous model, the heterogeneous model, and the fractional approach model. Note that these models have been re-derived multiple times in the literature, and therefore are not always referred to by these names. In the homogeneous model, the recrystallized fraction of the solid is assumed to always be in isotopic equilibrium with the fluid phase (Figure 2) (Doerner and Hoskins, 1925; Lahav and Bolt, 1964; Curti et al., 2005; Curti et al., 2010; Handler et al., 2014). In other words, once a portion of the mineral recrystallizes, it is assumed to re-equilibrate constantly (i.e., back react) with the fluid. Mathematically, this assumption yields a simple expression that can be used to calculate the fraction of the total solid that has recrystallized. In the case of a radioactive tracer $\left({ }^{k} A\right)$, the relationship most often utilized in the literature is:

$$
\frac{N_{{ }^{k} A_{(s)}}}{N_{A_{(s)}}^{e x c h}}=\frac{N_{{ } A_{(a q)}}}{N_{A_{(a q)}}}
$$
where, $N_{{ }_{A_{(i)}}}$ is the moles of radiotracer in phase $i, N_{A_{(i)}}$ is the total moles of element $\mathrm{A}$ in phase $i$, and $N_{A_{(s)}}^{e x c h}$ is the total moles of $A$ in the exchanged fraction of the solid. Note that massdependent isotope effects (i.e., the preferential release or sequestration of a nuclide based on mass) are often ignored because the isotopic gradient is so large that fractionation at the permil level is not relevant, but this equation can be adjusted to account for isotopic fractionation if 
Homogeneous model

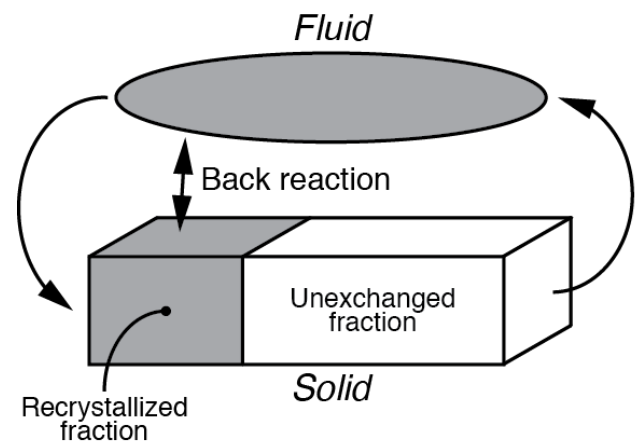

necessary (e.g., Handler et al., 2014). This equation also does not include radioactive decay, as decay is typically corrected for prior to applying the model. In this model, it is assumed that complete recrystallization has occurred when the solid and aqueous phases have identical isotopic compositions (neglecting mass-dependent isotope effects).

Figure 2. Schematic representing the heterogeneous and homogeneous recrystallization models at an arbitrary time point for a system in which a radioactive tracer $\left({ }^{k} A\right)$ is initially present in the fluid phase.

The gray shading indicates the isotopic enrichment of a phase $\left(N_{{ }_{k}} / N_{A}\right)$, as indicated in the legend

\section{Heterogeneous model}
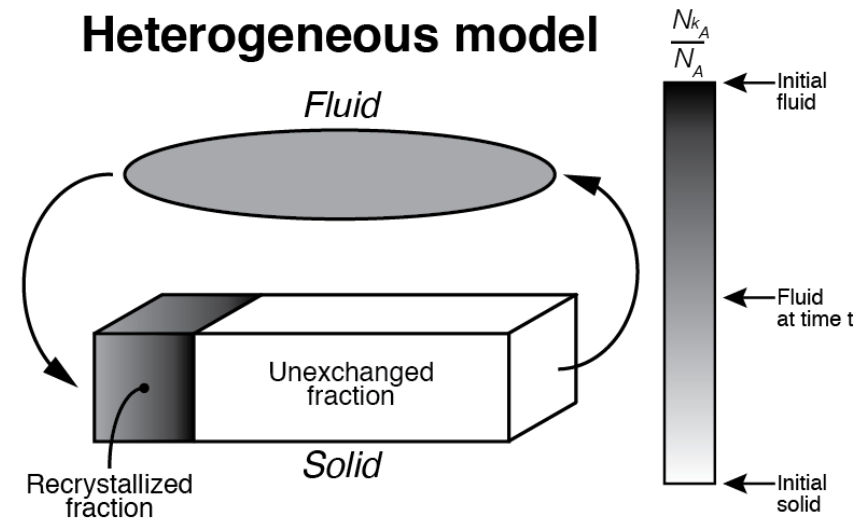
on the right.

The heterogeneous model differs from the homogeneous model in that it assumes no back reaction (i.e., re-equilibration) between the recrystallized fraction of the solid and aqueous phases after the initial recrystallization (i.e., tracer uptake) event (Figure 2) (Curti et al., 2005; Curti et al., 2010). As a result, the recrystallized fraction of the solid is assumed to have a range of isotopic compositions, which reflect the solution's isotopic composition at the time of the initial precipitation event. In the radiotracer case, this is expressed mathematically as:

$$
\mathrm{V} \frac{d\left[{ }^{k} A_{(a q)}\right]}{d t}=-\frac{d N_{A_{(s)}}^{e x c h}}{d t} \cdot \frac{\left[{ }^{k} A_{(a q)}(t)\right]}{\left[A_{(a q)}\right]}
$$

where square brackets denote concentration (units of moles/volume), $\mathrm{t}$ is time, $\mathrm{V}$ is the solution volume, and $N_{A_{(s)}}^{\text {exch }}$ is the moles of exchanged solid at time $t$. Radioactive decay can be included in this expression by adding another term to the right side of the equation (i.e., $-\lambda^{k} N_{A}$ ) (Curti et al., 2010). Given the initial condition that there is no tracer in the mineral (i.e., $\left.A_{(s)}^{\text {exch }}(t)=0\right)$, the solution to Eq. 8 is: 


$$
N_{A_{(s)}}^{\operatorname{exch}}(t)=\mathrm{V} \cdot\left[A_{(a q)}\right] \ln \left\{\frac{\left[{ }^{k} A_{(a q)}\right]_{0}}{\left[{ }^{k} A_{(a q)}\right]_{t}}\right\}
$$

where $\left[{ }^{k} A_{(a q)}\right]_{0}$ is the initial concentration of the tracer ${ }^{k} A$ in solution, and $\left[{ }^{k} A(a q)\right] t$ is the aqueous concentration of the radiotracer $\left({ }^{k} A\right)$ at time $t$. To calculate the fraction of the mineral that has recrystallized at time $\mathrm{t}, N_{A_{(s)}}^{\text {exch }}$ is divided by the total moles of element $\mathrm{A}\left(N_{A_{(s)}}\right)$ in the mineral. An important consequence of this model is that when the fluid and solid phases reach the same isotopic composition, exchange can still be incomplete because the recrystallized fraction of the mineral is not at isotopic equilibrium with the solution (Figure 2).

The homogeneous and heterogeneous models represent two end-member states with respect to the reactivity of the recrystallized solid. The homogeneous model assumes constant and instantaneous equilibration between the recrystallized fraction of the mineral and solution, while the heterogeneous model assumes no equilibration between the recrystallized fraction of the mineral and solution. An obvious additional possibility is that the recrystallized solid partially reacts with the solution, but it does not reach isotopic equilibrium over the time scale of the experiment. This scenario would produce a recrystallized solid phase that has an isotopic composition between that of the solution at time $t$ (i.e., the homogenous model) and the solution at which point the recrystallized phase formed (i.e., the heterogeneous model). To the best of our knowledge, no work has attempted to use such a model, likely because experiments are rarely designed with the explicit focus of testing the appropriate model used to fit data.

The third approach that has been used to interpret experimental recrystallization data is the fractional approach model (e.g., Duffield and Calvin, 1946; Norris, 1950). This approach has been most commonly used in stable isotope studies, with the fractional approach towards equilibrium (F) of a closed system calculated using:

$$
F=\frac{\delta_{s, t}-\delta_{s, i}}{\delta_{e}-\delta_{s, i}}
$$

where $\delta$ is shorthand for $\delta^{i / j} A$ (Eq. 3), and $\delta_{m, t}$ values refer to the isotopic compositions of the $m^{\text {th }}$ phase (solid, s, or aqueous, aq) at time, t. In Eq. 10, we define F in terms of the solid phase, where $\delta_{s, t}$ is the $\delta_{(\mathrm{s})}$ value of solid phase at time $t, \delta_{s, i}$ is the initial $\delta_{(\mathrm{s})}$ value of solid phase at $\mathrm{t}=0$, and $\delta_{e}$ is the $\delta$ value of the system when the solid and aqueous phases mix completely (i.e., have 
identical $\delta$ values). The $\delta_{e}$ value is calculated using a mass balance approach, assuming no isotopic fractionation and a closed system with no net mass transfer between the solid and aqueous phases:

$$
\delta_{\mathrm{e}}=\delta_{\mathrm{s}, i} X_{A_{(\mathrm{s})}}+\delta_{\mathrm{aq}, i} X_{A_{(\mathrm{aq})}}
$$

where $X$ is the mole fraction of element $A$ in the solid or fluid at some point in time. In the case of a sizeable isotope effect between solid and fluid $\left(\Delta_{s-a q}^{i / j}\right.$, the isotopic fractionation factor expressed in permil units), the isotopic composition of the final solid can be expressed as:

$$
\delta_{s, \text { final }}=\delta_{\mathrm{s}, i} X_{A_{(s)}}+\left(\delta_{\mathrm{aq}, i}+\Delta_{s-a q}^{i / j}\right) X_{A_{(a q)}} \quad \text { Eq. } 11 \mathrm{~b}
$$

What is clear from this expression is that if $X_{A_{(\mathrm{s})}} \gg X_{A_{(\mathrm{aq})}}$ (i.e., in a system with a high solid:fluid mass ratio), the solid does not change markedly relative to its initial state and therefore the isotopic effect will not be expressed in the solid relative to its initial state. Alternatively, if $X_{A_{(s)}}$ $\ll X_{A_{(\mathrm{aq})}}$ (i.e., in a system with a low solid:fluid mass ratio), then the isotopic effect will be more fully expressed relative to the initial solid (i.e., $\delta_{\mathrm{s}, f} \approx \delta_{\mathrm{aq}, i}+\Delta_{\mathrm{s}-\mathrm{aq}}^{i / j}$ ). While not significant in most tracer studies aimed at constraining solid-fluid exchange rates, such an observation does highlight the importance of monitoring both the solid and aqueous phases according to the design of a given experiment.

The fractional approach model was originally developed to describe the approach of a reacting system to isotopic equilibrium (McKay, 1938; Duffield and Calvin, 1946; Norris, 1950; Cole and Chakraborty, 2001). It was not, however, intended as an indicator of the fraction of the solid that has recrystallized. This distinction is important because the calculated $\mathrm{F}$ value is not necessarily the same as the fraction of the mineral that has recrystallized (Cole and Chakraborty, 2001; Handler et al., 2014). Approximating that F is equal the fraction of the solid that has recrystallized is equivalent to assuming that the recrystallized fraction of the solid has, at all times, an isotopic composition equal to $\delta_{e}$. Such a scenario is only realistic in situations where the fluid does not change over the course of the experiment. In cases where the fluid chemistry varies over time, the solid formed at any given time will reflect the fluid at that time (except when back-reaction is fast enough for the solid to track the fluid without a significant time lag). Because the fractional approach model only accurately estimates the fraction of the 
Fraction of tracer in fluid small.

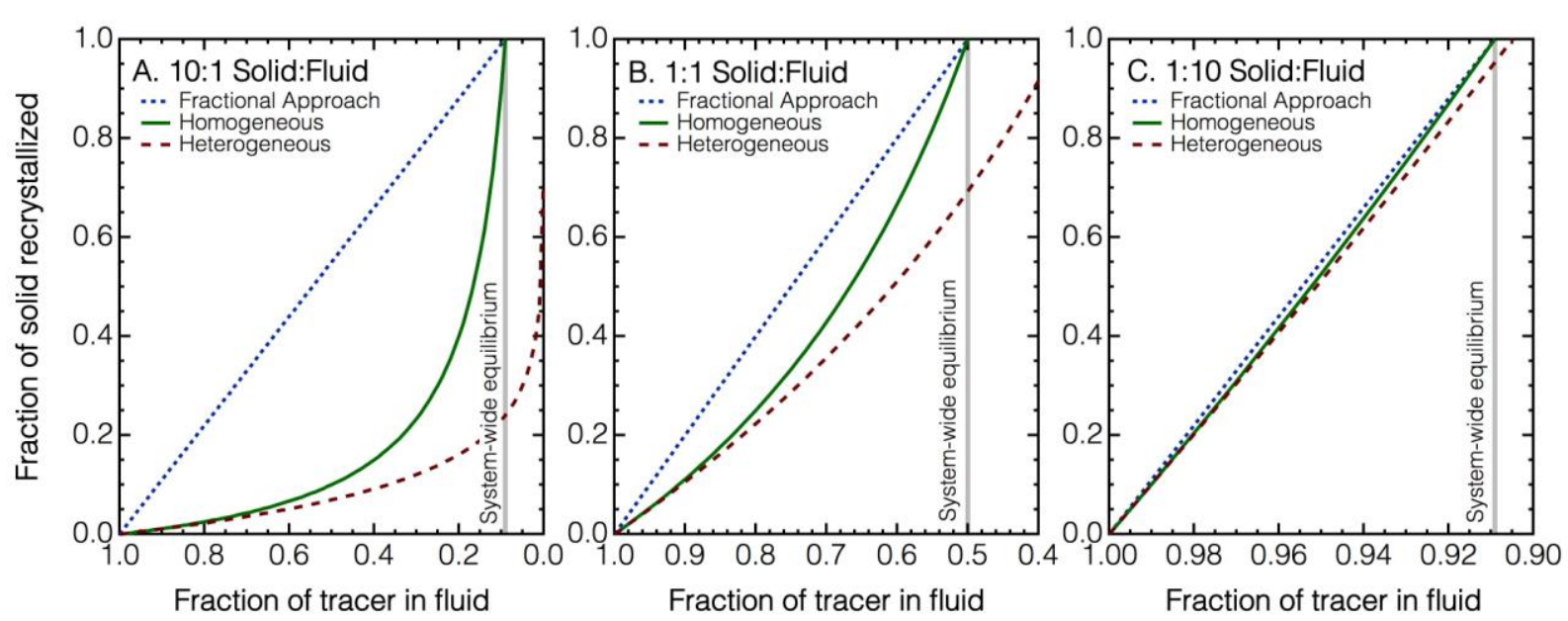

solid that has recrystallized under a narrow range of scenarios, we recommend that future works avoid using this model for estimating the extent of reaction.

Given the issues described above, it is clear that the model used to interpret exchange data can profoundly impact the inferred fraction of the mineral that has recrystallized (e.g., Curti et al., 2005; Curti et al., 2010; Handler et al., 2014). To illustrate this point, we compared each of the three models described above assuming an exchanging system comprised of solid and solution in which a radioactive tracer is initially present only in solution (Figure 3). We selected three cases with different mass ratios of the tracer element between the mineral and fluid phases (i.e., $N_{A_{(s)}}: N_{A_{(f)}}$ ) of 10:1 (Figure 3A), 1:1 (Figure 3B), and 1:10 (Figure 3C). This exercise highlights that when the solid:fluid mass ratio is larger than 1, the models significantly differ from one another (Figure 3A). In this case, the fractional approach predicts far more recrystallization than the other two models; there are also significant differences between the homogeneous and heterogeneous models, particularly when the fraction of tracer in solution is

Figure 3. Comparison of the calculated fractions of a solid that recrystallizes for the fractional approach, homogeneous, and heterogeneous models. In these calculations, the tracer was initially present in the solution phase. Three solid:fluid elemental mass ratios (mole of element in solid:mole of element in solution) are shown: 10:1 (A), 1:1 (B), and 1:10 (C). The gray lines represent the amount of tracer that would be in solution if the solid and aqueous phases had the same isotopic composition (i.e., $\delta_{\mathrm{e}}$ ).

Interestingly, when recrystallization proceeds to the point where the mineral and solid have the same isotopic compositions, as shown by the gray vertical lines, the homogeneous model calculates that the entire mineral has recrystallized (because it assumes that the recrystallized fraction of the solid is always in isotopic equilibrium with the solution). By 
contrast, the heterogeneous model estimates that $<100 \%$ of the mineral has recrystallized, because the recrystallized portion of the mineral never reaches the assumed equilibrated state. These differences become more pronounced as the solid to aqueous mass ratio increases, and less pronounced as it decreases. This is because the fluid is increasingly influenced by the dissolution of the solid at higher solid:fluid mass ratios. In the case of a 1:1 mass ratio (Figure 3B), the homogeneous model calculates that more of the mineral has recrystallized than the heterogeneous model, but the discrepancy is significantly smaller than that in the 10:1 case. When the solid:fluid mass ratio is $1: 10$, and thus the leverage of the solid to alter the fluid is small, the models yield nearly identical calculated extents of mineral recrystallization. Collectively, these observations highlight the importance of model selection on data interpretation, particularly when the solid:fluid mass ratio is larger than 1 (or even differs from experiment to experiment).

Determining which of these models most accurately represents reality has proven to be a difficult task because of technical challenges, which has been discussed extensively in the literature (Criss et al., 1987; Dubinina and Lakshtanov, 1997; Cole and Chakraborty, 2001; Curti et al., 2005; Curti et al., 2010; Avrahamov et al., 2013; Handler et al., 2014). The most straightforward way to test the models would be to collect complementary data that spatially resolves the isotopic composition of the solid. However, such analyses are rarely feasible because existing methods that can in principle perform such analyses, such as secondary ion mass spectrometry (SIMS), generally have insufficient precision at high spatial resolution.

In lieu of direct measurements, researchers have attempted to spatially resolve the isotopic compositions of a recrystallized solid using sequential chemical extractions (Handler et al., 2014). When such analyses have been done, the data provides qualitative insights into the isotopic composition of the solid as a function of solubility. Quantitatively interpreting the data has proven more difficult, however, for two reasons. First, it is difficult to assess the extent to which interfacial atom exchange occurs between the extracted atoms and atom still bound to the solid during the extraction procedure. Second, it is challenging to assess what property of a mineral is being probed during the extraction. The basic principle in chemical extractions - with the exception of sampling the sorbed component - is that they sample the solid based on 
fundamental difference is mineralogy, such as the relative solubilities or crystallinities of different portions of the solid. If stable mineral recrystallization does not alter or selectively affect the relative solubilities or crystallinities of portions of the solid, then it is difficult to link chemical extraction data to recrystallization extents in a quantitative way. Despite these shortcomings, this approach is still useful due to the lack of better approaches.

Due to the inability to determine what model is most appropriate based on complementary data, the interpretive model is most commonly selected using an indirect approach in which experimental data is fit with each model and the goodness-of-fit parameters (e.g., $\mathrm{R}^{2}$ values) are compared using least squares regression analyses (Curti et al., 2010; Avrahamov et al., 2013). An additional challenge in applying these models to experimental data is that the models are often founded on the assumption that the recrystallization rate remains constant over time. Given that experimental evidence indicates that recrystallization rates slow over time, this assumption may not always be valid (a topic discussed in detail later in the review).

We suggest an additional method to resolve the appropriate interpretive model. Parallel recrystallization experiments can be conducted in which the solid:fluid mass ratio (i.e., the ratio of the mass of the element of interest in the solid phase relative to the fluid phase) is systematically varied. At low solid:fluid mass ratios $(\ll 1)$, all the models will yield similar calculated values for the fraction of mineral recrystallized (Figure 3C). This calculated value should therefore be "accurate" (i.e., model independent), insofar as the mechanism in operation in captured by one of the models applied. At high solid:fluid mass ratios (>>1), each model will yield substantially different calculated fractions (Figure 3A). If one assumes that the fraction of mineral that recrystallizes in an experiment is a property of the mineral (and not the solid:fluid mass ratio), the calculated fraction of recrystallization should be the same in the high and low solid:fluid mass ratio experiments, and therefore this comparison can provide indirect insights into which model is the most appropriate representation of reality. Of course, the reliability of this approach depends on (1) the accuracy of the assumption that the solid:fluid mass ratio does not influence the fraction of the mineral that is capable of recrystallizing, and (2) that the models used represent the mechanism of the recrystallization process. 
Because the model used to calculate recrystallization rates and extents can strongly affect calculated recrystallization rates and extents, particularly when the solid:fluid ratio is high, we have (in this review) drawn attention to the interpretive model used in past studies. In cases in which the fractional approach model was used, we have re-calculated the recrystallization extent (when possible) using an alternative model because (1) the fractional approach model can yields unrealistic estimations of the fraction of the solid that has recrystallized, and (2) the exercise illustrates the magnitude of the difference between the calculated extents for each model. In cases in which the fractional approach model was used to calculate recrystallization extents, but there was insufficient data in the original manuscript to re-interpret it with the homogeneous model, we have simply presented the value obtained from the fractional approach model. We reason that, in systems with high solid:fluid ratios, this calculated recrystallization extent was likely an overestimate.

\subsection{Laboratory observations of stable mineral recrystallization}

Stable mineral recrystallization has been observed in laboratory studies for two classes of mineral-water interactions. The first is redox-inactive stable mineral recrystallization, in which ions of the same valence state exchange between the mineral and aqueous phase (e.g., $\mathrm{Ca}^{2+}$ atom exchange between calcium carbonate $\left(\mathrm{CaCO}_{3}\right)$ and dissolved $\left.\mathrm{Ca}^{2+}\right)$. This interaction is commonly studied by placing an aliquot of the mineral in a solution that is saturated with respect to the mineral and tracking the evolution of the solid and fluid over time. The saturated solution is typically created by allowing the solid and fluid to react for long periods of time, thereby minimizing the potential for net precipitation and/or dissolution reactions that can affect the isotopic compositions of the mineral and solution. The second interaction of interest is redoxactive stable mineral recrystallization, in which ions of different valence state exchange between the mineral and aqueous phase (e.g., iron atoms exchanging between ferric iron $\left(\mathrm{Fe}^{3+}\right)$ in goethite $(\alpha-\mathrm{FeOOH})$ and dissolved $\left.\mathrm{Fe}^{2+}\right)$. Redox-active stable mineral recrystallization experiments are conducted under apparent redox equilibrium conditions between the solution and mineral. Since the underlying mechanisms and thermodynamics driving redox-inactive and redox-active stable mineral recrystallization may be fundamentally different, we discuss the 
two classes of observations separately. A catalog of the previous studies examining redoxinactive and redox-active systems is provided in Table $\mathbf{1}$ for reference.

Table 1. A catalog of past stable mineral recrystallization laboratory studies organized by mineral. Studied denoted with a "*” indirectly studied stable mineral recrystallization by tracking the fate of a trace element. Minerals marked with "†" are technically unstable with respect to other mineral phases and therefore do not meet the criteria for stable mineral recrystallization as defined in Section 1.1, but we have included them in this summary and discussion for the sake of completeness.

\begin{tabular}{|c|c|c|}
\hline & Mineral & References \\
\hline \multirow{6}{*}{ 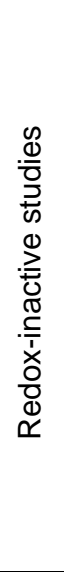 } & Calcite $\left(\mathrm{CaCO}_{3}\right)$ & $\begin{array}{l}\text { (Lahav and Bolt, 1964; McBride, 1980*; Mozeto et al., 1984; Davis et } \\
\text { al., 1987; Zachara et al., 1991; Stipp et al., 1992*; Das et al., 1995; } \\
\text { Carlsson and Aalto, 1997; Cheng et al., 1997*; Reeder et al., 2004*; } \\
\text { Curti et al., 2005*; Elzinga et al., 2006*; Heberling et al., 2008*; } \\
\text { Avrahamov et al., 2013; Heberling et al., 2014) }\end{array}$ \\
\hline & Barite $\left(\mathrm{BaSO}_{4}\right)$ & $\begin{array}{l}\text { (Bosbach et al., 2010; Curti et al., 2010; Vinograd et al., 2013; } \\
\text { Klinkenberg et al., 2014*; Brandt et al., 2015*) }\end{array}$ \\
\hline & Gypsum $\left(\mathrm{CaSO}_{4}\right)$ & (Lestini et al., 2013) \\
\hline & Dolomite $\left(\mathrm{CaMg}\left(\mathrm{CO}_{3}\right)_{2}\right)$ & (Lahav and Bolt, 1964; Malone et al., 1996) \\
\hline & Ferrihydrite $^{\dagger}$ & (Rea et al., 1994; Poulson, 2005) \\
\hline & Mackinawite $(\mathrm{FeS})^{\dagger}$ & (Guilbaud et al., 2011) \\
\hline \multirow{6}{*}{ 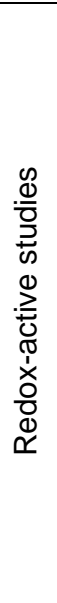 } & Goethite $(\alpha-\mathrm{FeOOH})$ & $\begin{array}{l}\text { (Crosby et al., 2005; Pedersen et al., 2005; Handler et al., 2009; Beard } \\
\text { et al., 2010; Frierdich et al., 2011*; Frierdich and Catalano, 2012a*; } \\
2012 b^{*} ; \text { Frierdich et al., 2012*; Latta et al., 2012a; Latta et al., 2012b*; } \\
\text { Frierdich et al., 2014a; Handler et al., 2014; Frierdich et al., 2015a; } \\
\text { Hinkle and Catalano, 2015*; Pasakarnis et al., 2015; Reddy et al., } \\
\text { 2015) }\end{array}$ \\
\hline & Magnetite $\left(\mathrm{Fe}_{3} \mathrm{O}_{4}\right)$ & (Gorski et al., 2012; Frierdich et al., 2014b) \\
\hline & Hematite $\left(\alpha-\mathrm{Fe}_{2} \mathrm{O}_{3}\right)$ & $\begin{array}{l}\text { (Pedersen et al., 2005; Frierdich et al., 2011*; Frierdich and Catalano, } \\
2012 a^{*} ; 2012 b^{*} ; \text { Frierdich et al., 2012*; Frierdich et al., 2015b) }\end{array}$ \\
\hline & Si-stabilized Ferrihydrite ${ }^{\dagger}$ & (Wu et al., 2012) \\
\hline & Manganite $(\mathrm{Y}-\mathrm{MnOOH})$ & (Frierdich et al., 2016) \\
\hline & Vernadite $(\delta-\mathrm{MnO} 2)$ & (Elzinga, 2016) \\
\hline
\end{tabular}

\subsubsection{Redox-inactive stable mineral recrystallization}

Perhaps the clearest laboratory-based observation of redox-inactive stable mineral recrystallization comes from experiments examining barite $\left(\mathrm{BaSO}_{4}\right)$ in saturated solutions. Curti et al. (2010) allowed barite crystals approximately $10 \mu \mathrm{m}$ in diameter to exchange at room temperature with aqueous solutions containing radioactive ${ }^{133} \mathrm{Ba}^{2+}$. In two of the experimental conditions analyzed containing $1 \mathrm{~g} / \mathrm{L}$ barite, the mass of ${ }^{133} \mathrm{Ba}^{2+}$ in solution dropped sharply over 


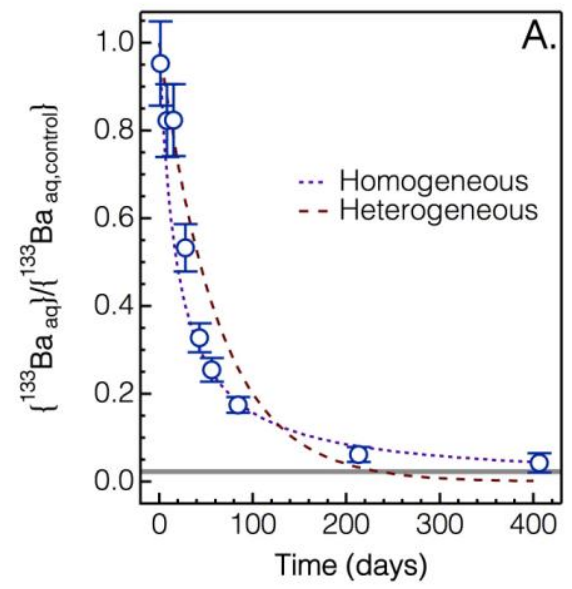
days.

time and approached a value indicating that the solid and solution reached complete isotopic mixing after 400 days (Figures $\mathbf{4 A}$ and $\mathbf{4 B}$; the gray line indicates complete isotopic mixing between the solid and solution). In a third experiment containing a lower barite concentration $(0.01 \mathrm{~g} / \mathrm{L})$ than in the other two experiments (Figure $4 \mathrm{C})$, the dissolved concentration of ${ }^{133} \mathrm{Ba}^{2+}$ also substantially decreased, but did not approach the complete isotopic mixing line over 300

Figure 4. Fractional activity of ${ }^{133} \mathrm{Ba}^{2+}$ remaining in the aqueous phase in for three experiments containing isotopically-normal barite over time. The dissolved activity was corrected for sorption on the reactor walls and ${ }^{133} \mathrm{Ba}^{2+}$ decay by relating the activity to a control reactor containing no barite (i.e., ${ }^{133} \mathrm{Ba}_{\mathrm{aq}, \mathrm{contro}}$ ). Error bars represent one standard deviation in measurements. The gray lines represent the calculated dissolved ${ }^{133} \mathrm{Ba}^{2+}$ if the solid and solution had the same isotopic composition. The red dashed line is the data fit using the homogenous model, and the purple dotted line is the data fit using the heterogeneous

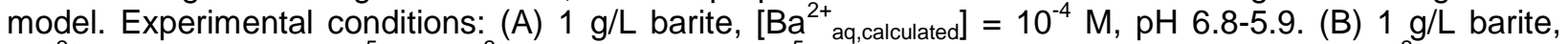
$\left[\mathrm{Ba}^{2+}{ }_{\text {aq,calculated }}\right]=1.1 \times 10^{-5} \mathrm{M},\left[\mathrm{Ba}^{2+}{ }_{\text {aq,measured }}\right]=1.4 \times 10^{-5} \mathrm{M}, \mathrm{pH}=5.3-4.7$. (C) $0.01 \mathrm{~g} / \mathrm{L}$ barite, $\left[\mathrm{Ba}^{2+}{ }_{\text {aq, calculated }]}\right]$ $=3.5 \times 10^{-7} \mathrm{M},\left[\mathrm{Ba}^{2+}{ }_{\text {aq, measured }}\right]=2.9 \times 10^{-7} \mathrm{M}, \mathrm{pH}=8.2-8.3$. The paper contains additional experimental details. Data from Geochimica et Cosmochimica Acta, Vol. 74, E. Curti, K. Fujiwara, K. lijima, J. Tits, C. Cuesta, A. Kitamura, M.A. Glausa, W. Müller. Radium uptake during barite recrystallization at $23 \pm 2{ }^{\circ} \mathrm{C}$ as a function of solution composition: An experimental ${ }^{133} \mathrm{Ba}$ and ${ }^{226} \mathrm{Ra}$ tracer study, Pages 3553-3570, Copyright 2010, with permission from Elsevier.

The datasets in Figure 4 were best fit using the homogeneous model (dotted line). Attempts to model the data using the heterogeneous model resulted in visually poor fits that did not capture the temporal trends of the data (dashed line) (Curti et al., 2010). The data could also be accurately fit using the heterogeneous if the recrystallization rate was assumed to slow over time (not shown) (Curti et al., 2010). The difference in the ability of the two models to capture the temporal evolution of the fluid suggests that the recrystallized fraction continued to react with the solution after it formed or that the recrystallization rate decreased over time. 
Modeling the data in Figure 4 with the homogeneous model (Eq. 7) indicated that 53\% of the barite in A recrystallized, $45 \%$ of the barite in B recrystallized, and $5 \%$ of the barite in C recrystallized. For all three experiments, these percentages were greater than the expected number of $\mathrm{Ba}$ atoms on the barite surface (A: 513 monolayer equivalents, $\mathrm{B}: 351$ monolayer equivalents, C: 26 monolayer equivalents), indicating that Ba atoms initially deep within the mineral lattice recrystallized over the course of the reaction.
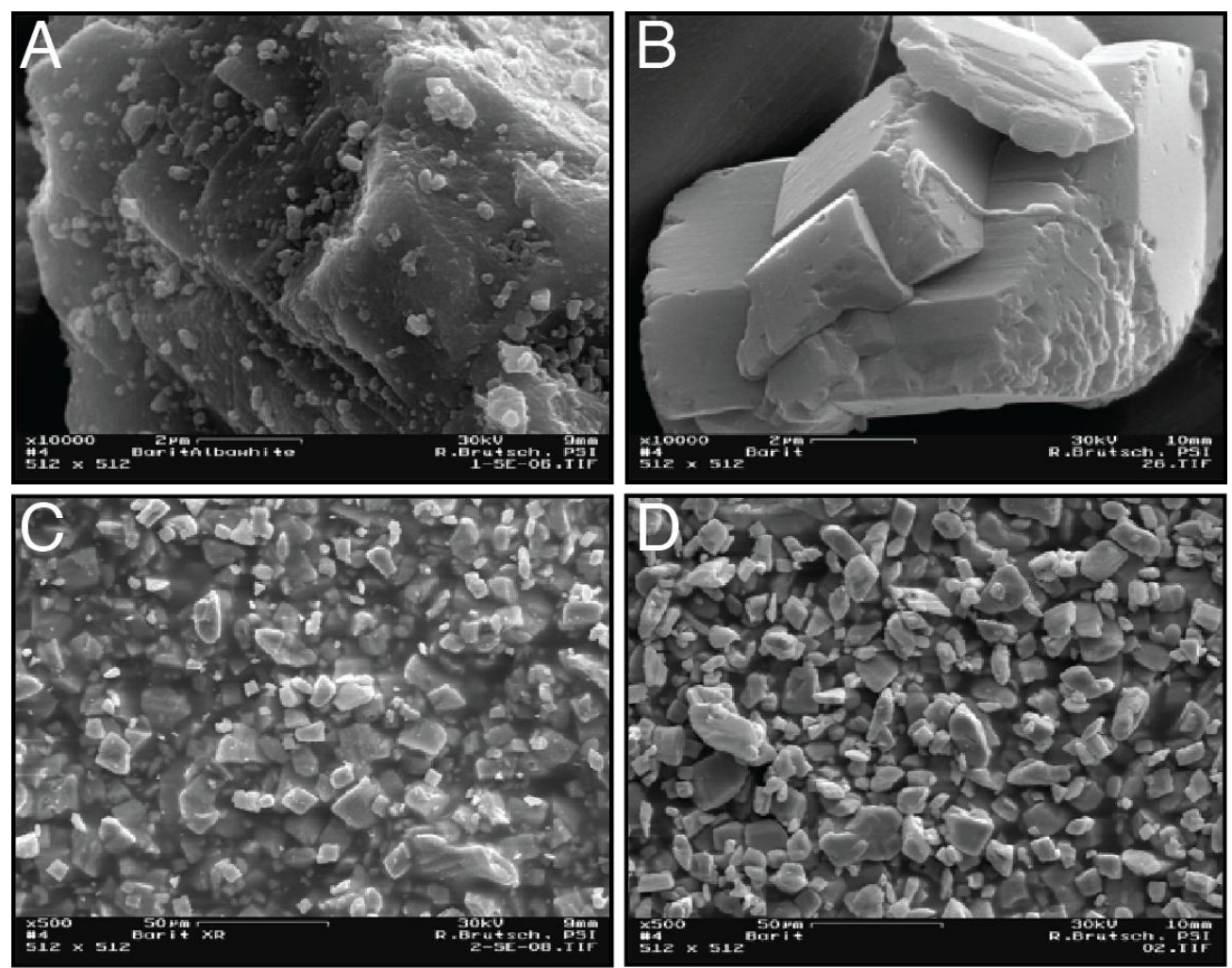

Figure 5. Scanning electron microscopy images of the barite used in Curti 2010 before ( $A$ and $C)$ and after exposure to deionized water for 18 months (B and $D)$. Over the course of the reaction, the small nanoscale barite particles on the top of the large crystals disappeared, and the surface roughness decreased $(A$ and $B)$. The average grain size did not change over the course of the reaction ( $C$ and D). Data from Geochimica et Cosmochimica Acta, Vol. 74, E. Curti, K. Fujiwara, K. lijima, J. Tits, C. Cuesta, A. Kitamura, M.A. Glausa, W. Müller. Radium uptake during barite recrystallization at $23 \pm 2$ ${ }^{\circ} \mathrm{C}$ as a function of solution composition: An experimental ${ }^{133} \mathrm{Ba}$ and ${ }^{226} \mathrm{Ra}$ tracer study, Pages $3553-$ 3570, Copyright 2010, with permission from Elsevier.

While the isotopic data indicated that extensive barite recrystallization occurred, the morphology of the barite crystals did not substantially change. Scanning electron microscopy (SEM) images of the barite crystals (Figure 5) revealed that the overall particle dimensions and morphology were the same at the beginning of the experiment and after 18 months equilibration in deionized water (Figures 5C and 5D). Individual particles did exhibit a 
decrease in surface roughness, and nanoparticles originally on the barite surface disappeared (Figures 5A and 5B). Other works have observed similar particle "smoothing" without any indication of an increase in particle size in stable mineral recrystallization studies examining calcite (Avrahamov et al., 2013) and gypsum (Lestini et al., 2013). Because the particles did not appear to grow, Ostwald Ripening was ruled out as a potential mechanism for the observed recrystallization. Likewise, solid-state diffusion was dismissed because recrystallization occurred far faster than would be expected based on reported diffusion coefficients. Instead, the authors concluded that recrystallization proceeded through a yet to be identified mechanism. Since the publication of this study, subsequent works have corroborated these observations of extensive recrystallization using additional barite specimens and a wider range of solution conditions (Bosbach et al., 2010; Vinograd et al., 2013).

Similar observations of redox-inactive stable mineral recrystallization - in which substantial isotopic exchange occurs between the mineral and solution without overt changes in the mineral's structure or morphology based on direct observations or expectations from previous studies - have been made for several commonly occurring and environmentally relevant minerals in low temperature aqueous experiments, including calcite $\left(\mathrm{CaCO}_{3}\right)(\mathrm{Lahav}$ and Bolt, 1964; Mozeto et al., 1984; Davis et al., 1987; Zachara et al., 1991; Das et al., 1995; Carlsson and Aalto, 1997; Curti et al., 2010; Avrahamov et al., 2013; Heberling et al., 2014), gypsum $\left(\mathrm{CaSO}_{4}\right)$ (Lestini et al., 2013), dolomite $\left(\mathrm{CaMg}\left(\mathrm{CO}_{3}\right)_{2}\right)$ (Lahav and Bolt, 1964; Malone et al., 1996), ferrihydrite (Rea et al., 1994; Poulson, 2005), and mackinawite (FeS) (Guilbaud et al., 2011) (Table 1). Further evidence of redox-inactive stable mineral recrystallization can be derived from observations of trace elements initially present in solution becoming structurally incorporated into a mineral lattice. For example, numerous studies have observed that trace elements will sorb and subsequently incorporate into barite (Bosbach et al., 2010; Curti et al., 2010; Vinograd et al., 2013; Klinkenberg et al., 2014) and calcite (McBride, 1980; Davis et al., 1987; Stipp et al., 1992; Cheng et al., 1997; Reeder et al., 2004; Curti et al., 2005; Elzinga et al., 2006; Heberling et al., 2008; Heberling et al., 2014) over time scales of months. The primary focus of many of these studies was to understand the mechanisms and extents to which trace elements are structurally incorporated into the mineral lattice over time (Lahav and Bolt, 1964; 
Davis et al., 1987; Zachara et al., 1991; Rea et al., 1994; Das et al., 1995; Carlsson and Aalto, 1997). More recently, studies have been motivated by how this process influences the fate of radionuclides in radioactive waste storage facilities (Curti et al., 2005; Bosbach et al., 2010; Curti et al., 2010; Lestini et al., 2013; Vinograd et al., 2013).

Studies have also focused on the effect that stable mineral recrystallization has on the isotopic compositions of minerals and a coexisting fluid. Researchers have studied how recrystallization influences the carbon isotopic composition $\left({ }^{14} \mathrm{C} /{ }^{12} \mathrm{C}\right)$ of bicarbonate in groundwater, which impacts the utility of techniques for dating groundwater in carbonate-rich aquifers (Mozeto et al., 1984; Avrahamov et al., 2013). These studies concluded that recrystallization is sufficiently rapid to offset the isotopic composition of the groundwater significantly, although the rate strongly depends on the ratio of available mineral surface area to water volume (i.e., the isotopic composition of the dissolved carbonate is more affected when there is a lower ratio of water to exposed rock surface). The primary objective of studies examining dolomite was to understand the genesis, pathways, and rates of dolomite formation, as well as post-formational alteration, in order to assess its suitability as a proxy (Lahav and Bolt, 1964; Malone et al., 1996). Similarly, studies of iron minerals have been conducted to constrain the equilibrium isotopic fractionation factor between ferrihydrite and aqueous $\mathrm{Fe}^{3+}$ (Poulson, 2005) as well as mackinawite (FeS) and aqueous $\mathrm{Fe}^{2+}$ (Guilbaud et al., 2011) to aid interpretation of the Fe isotopic composition of pyrite in the rock record over geologic time scales. Note that mackinawite is less thermodynamically stable than pyrite and that ferrihydrite is less thermodynamically stable than other iron oxides and hydroxides, and therefore recrystallization reactions involving these minerals are not strictly "stable mineral recrystallization" as we have defined it here. We included these minerals in the present discussion to be comprehensive and because the minerals did not undergo mineral transformations during the experiments. 
Table 2. Reported redox-inactive recrystallization rates for barite, calcite, and gypsum.

\begin{tabular}{lcccc}
\hline Mineral & Recrystallization rate $\left(\mathbf{m o l} / \mathbf{m}^{2} \mathbf{y r}\right)$ & Temperature & Model & Study \\
\hline Barite & $1.8 \times 10^{-2}-8.8 \times 10^{-4, a}$ & $20^{\circ} \mathrm{C}$ & Homogeneous & $\begin{array}{c}\text { (Curti et al., } \\
2010)\end{array}$ \\
\hline Calcite & $1.0 \times 10^{-4}-2.9 \times 10^{-4, \mathrm{~b}}$ & Room Temp & Heterogeneous & $\begin{array}{c}\text { (Curti et al., } \\
2005)\end{array}$ \\
\hline Calcite & $3.5 \times 10^{-5}-7 \times 10^{-6}, 9 \times 10^{-4}-7 \times 10^{-5, \mathrm{c}}$ & Room Temp & Homogeneous & $\begin{array}{c}\text { (Avrahamov et } \\
\text { al., 2013) }\end{array}$ \\
\hline Gypsum & $1.5 \times 10^{-3}, 3.7 \times 10^{-3}$ & $40{ }^{\circ} \mathrm{C}$ & Heterogeneous & $\begin{array}{c}\text { (Lestini et al., } \\
2013)\end{array}$ \\
$\begin{array}{l}\text { Rates varied depending on solution conditions and barite concentrations. } \\
\text { The data were modeled with two-stage kinetics. }\end{array}$ \\
$\begin{array}{l}\text { The data were modeled with two-stage kinetics. The first set of rates was collected for freshwater } \\
\text { solutions; the second set of rates was collected for a synthetic dead-sea brine. }\end{array}$
\end{tabular}

Among the studies that observed redox-inactive stable mineral recrystallization, a small subset reported surface-area normalized reaction rates, which range between $10^{-2}$ to $10^{-6}$ $\mathrm{mol} / \mathrm{m}^{2} \mathrm{yr}$ (Table 2). The reason for this rather narrow range is likely that recrystallization rates slower than $10^{-6} \mathrm{~mol} / \mathrm{m}^{2} \mathrm{yr}$ are difficult to detect over experimental time scales of a year or less. Consequently, it is challenging to distinguish between a mineral that does not recrystallize and one that does at a rate too slow to measure in laboratory-based experiments.

The relative kinetics of recrystallization have been found to depend on several factors, including (1) temperature (Malone et al., 1996; Cole and Chakraborty, 2001), (2) the solution chemistry (Mozeto et al., 1984; Curti et al., 2010; Avrahamov et al., 2013), and (3) the mineral specimen used (i.e., synthetic or natural) (Mozeto et al., 1984; Gonfiantini and Zuppi, 2003; Bosbach et al., 2010; Avrahamov et al., 2013). Calcite recrystallization occurred approximately ten times faster in freshwater than in hypersaline brines, which was attributed to the salt ions slowing dissolution by inhibiting the removal of $\mathrm{CO}_{3}{ }^{2-}$ from the mineral surface (Avrahamov et al., 2013). Calcite recrystallization was also slower in the presence of aqueous $\mathrm{Mg}^{2+}$, which was attributed to its role in inhibiting dissolution as well (Mozeto et al., 1984). With respect to the mineral itself, studies have found that different mineral specimens recrystallize at different rates (Mozeto et al., 1984; Gonfiantini and Zuppi, 2003; Bosbach et al., 2010; Avrahamov et al., 2013). Natural calcite specimens recrystallized at slower rates than chemically prepared calcites (Mozeto et al., 1984; Avrahamov et al., 2013), suggesting that differences in defects or surface structures affect recrystallization. Collectively, these observations offer indirect insights into the 
how solution conditions and mineral properties affect recrystallization rates, but the mechanisms underlying these trends remain unclear.

A critical and common observation among studies examining redox-inactive recrystallization is that rates slow over time. Recrystallization is generally initially rapid over the first few days of the experiment, but becomes slower over longer time periods (Mozeto et al., 1984; Rea et al., 1994; Curti et al., 2005; Bosbach et al., 2010; Wu et al., 2011; Avrahamov et al., 2013; Lestini et al., 2013). In studies that quantified the recrystallization rates for these two kinetic domains, the initial rapid rate was approximately one order of magnitude faster than the rate over longer time scales (Table 2). Interestingly, two-stage kinetics has been observed even when the mineral specimen is pre-equilibrated in solution for periods of four weeks or greater prior to adding the isotopic tracer (Mozeto et al., 1984; Bosbach et al., 2010; Avrahamov et al., 2013). This indicates that the initial rapid exchange reflects exchange between surface atoms and dissolved ions, which is likely a perpetual process at equilibrium. In fact, one study suggested that the data gathered from this initial rapid isotopic exchange could be used to estimate the reactive surface area of calcite in water (Inks and Hahn, 1967). Over longer periods of time (> 1 month), recrystallization rates continue to slow. Evidence for this continued slowing comes from experiments in which the isotope tracer was added to the solution at multiple time points (Mozeto et al., 1984; Avrahamov et al., 2013). In these studies, tracer uptake slowed with each addition of tracer. The most plausible explanation for these findings is that the mineral specimen becomes more stable and therefore less reactive over time.

Since recrystallization rates change over time, it is often difficult to estimate how much recrystallization could occur over long time scales that exceed the practical limitations of experimental measurements ( $>1$ year). In virtually all experiments conducted to date, recrystallization appears to still be occurring when the reaction is terminated. One exception to this trend is a study by Poulson et al. (2005), which examined isotopic exchange between nanoparticulate ferrihydrite $(3 \mathrm{~nm})$ and $\mathrm{Fe}^{3+}$ in a saturated solution for 12 weeks. Rapid recrystallization occurred for the first 11 days, but then stopped for the remainder of the experiment. Using the homogenous model, the authors estimated that $26 \pm 5 \%$ of the ferrihydrite recrystallized, suggesting that only surface atoms participated in the recrystallization reaction. 
The ability for this system to equilibrate so quickly was likely due to the tiny dimensions of the ferrihydrite particles. Note that many studies for carbonates and sulfates use far larger particles, with dimensions that exceed $1 \mu \mathrm{m}$.

These studies collectively show that several minerals may undergo extensive redoxinactive recrystallization reactions under laboratory conditions over relatively short periods of time. In the following section, we discuss observations of redox-active stable mineral recrystallization. Our interest in comparing these two classes of reactions is partially motivated by the need to determine if they occur through a universal reaction mechanism or involve different processes.

\subsubsection{Redox-active stable mineral recrystallization}

Studies examining stable mineral recrystallization reactions for redox-active systems have primarily focused on interactions between stable $\mathrm{Fe}^{3+}$-bearing (oxyhydr)oxides and aqueous $\mathrm{Fe}^{2+}$ (Crosby et al., 2005; Pedersen et al., 2005; Handler et al., 2009; Jones et al., 2009; Beard et al., 2010; Wu et al., 2010; Wu et al., 2011; Frierdich and Catalano, 2012a; Gorski et al., 2012; Latta et al., 2012a; Latta et al., 2012b; Wu et al., 2012; Frierdich et al., 2014a; Frierdich et al., 2014b; Handler et al., 2014; Frierdich et al., 2015a; Frierdich et al., 2015b; Pasakarnis et al., 2015; Reddy et al., 2015; Joshi and Gorski, 2016). Recent work has found that found that manganese oxides (i.e., manganite $(\gamma-\mathrm{MnOOH})$ and vernadite $\left.\left(\delta-\mathrm{MnO}_{2}\right)\right)$ also recrystallize in the presence of aqueous $\mathrm{Mn}^{2+}$ without undergoing a phase transformation (Elzinga, 2016; Frierdich et al., 2016). While works have also observed redox-active recrystallization reactions between aqueous $\mathrm{Fe}^{2+}$ and thermodynamically unstable iron oxides (Jones et al., 2009), aqueous $\mathrm{U}^{6+}$ and $\mathrm{UO}_{2(\mathrm{~s})}$ (Wang et al., 2015b), aqueous $\mathrm{Cr}^{6+}$ and solid-phase $\mathrm{Cr}^{3+}$ (Wang et al., 2015a), and aqueous $\mathrm{Fe}^{2+}$ and $\mathrm{Fe}^{3+}-$ bearing clay minerals (Neumann et al., 2015), they have been excluded from the present discussion because either a mineral transformation occurred or the possibility of one occurring could not be ruled out based on characterization of the solid phase after the reaction. Generally, studies examining stable mineral recrystallization reactions have been motivated by the need to (1) illuminate the interactions that occur during interfacial electron transfer processes, (2) quantify the influence of stable mineral recrystallization on the fate and transport of trace 
metals and contaminants, and (3) constrain equilibrium isotopic fractionation factors used to interpret the isotopic compositions of rocks for paleoclimate reconstructions.

The data collected in redox-active recrystallization studies with iron oxides differ in three important ways from data collected in redox-inactive studies. First, the iron oxides used often have far larger specific surface areas $\left(>10 \mathrm{~m}^{2} / \mathrm{g}\right)$ than the minerals used in redox-inactive studies $\left(\leq 1 \mathrm{~m}^{2} / \mathrm{g}\right)$. As a result, it is important to surface-area normalize rates and extents over time when making comparisons among studies. Second, the system is rarely at equilibrium when the experiment begins. In the case of iron oxides, an $\mathrm{Fe}^{3+}$-bearing oxide is added to a solution containing aqueous $\mathrm{Fe}^{2+}$ to initiate the experiment. Within a few days, the oxide takes up a large fraction of the aqueous $\mathrm{Fe}^{2+}$ from solution (e.g., Handler et al., 2009). Consequently, there is an initial period of disequilibrium that may lead to interfacial isotopic exchange that is discretely different from the exchange that occurs once the system has reached an apparent equilibrium. Third, the majority of studies conducted to date with iron oxides used high solid:fluid mass ratios $(>10)$, meaning that calculated recrystallization extents strongly depend on the model used, as discussed in Section 2.1 and illustrated in Figure 3A.

Of the iron oxides examined in recrystallization studies, the majority of work has focused on goethite $(\alpha-\mathrm{FeOOH})$, which undergoes extensive and rapid recrystallization in the presence of aqueous $\mathrm{Fe}^{2+}$ at circumneutral pHs. In a seminal study by Handler et al. (2009), the authors observed that when they exposed isotopically-normal nano-particulate goethite (110 $\mathrm{m}^{2} / \mathrm{g} ; \delta^{57 / 56} \mathrm{Fe}=-0.12 \%$ o $)$ to aqueous $\mathrm{Fe}^{2+}$ enriched with ${ }^{57} \mathrm{Fe}\left(\delta^{57 / 56} \mathrm{Fe}=840.43 \%\right.$ ) under anaerobic conditions, the two phases approached the mass-weighted isotopic equilibrium after only 30 days $\left(\delta^{57 / 56} \mathrm{Fe}_{\text {eq }}=39.94\right)$, providing evidence that the a significant fraction of the Fe in the goethite recrystallized over the course of the experiment (Figure 6). To determine if and how the morphology of the goethite particles changed during this reaction, the authors collected transmission electron microscopy (TEM) images of the particles reacted with aqueous $\mathrm{Fe}^{2+}$ as well as particles from a control reactor that did not contain $\mathrm{Fe}^{2+}$ (Figure 7). A comparison of the mean particle lengths and widths for several images collected for each reactor revealed that the particle dimensions were statistically similar, indicating that $\mathrm{Fe}^{2+}$ did not cause any overt changes to the particle morphology or particle sizes. While this study was not the first to 

and oxides' isotopic compositions.

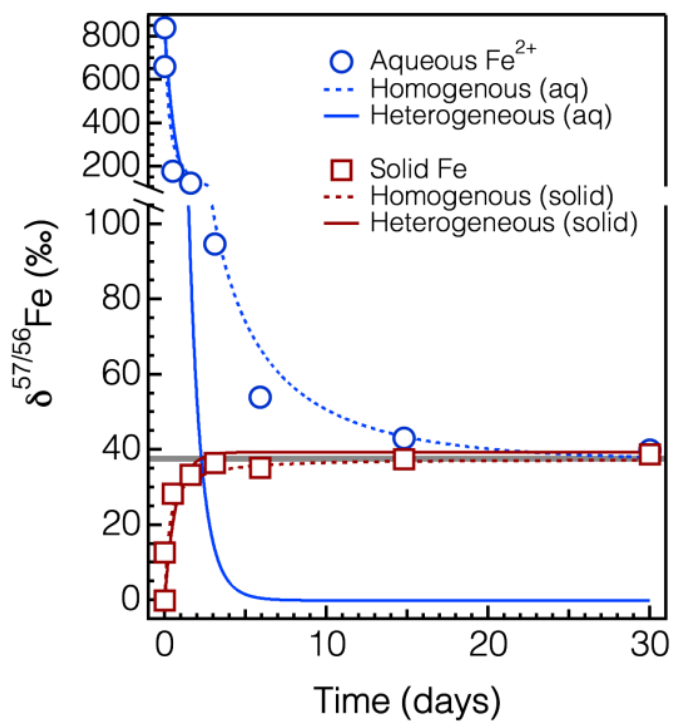

Figure 6. $\delta^{57 / 56} \mathrm{Fe}$ values for aqueous $\mathrm{Fe}^{2+}$ and solid $\mathrm{Fe}$ (goethite + sorbed $\mathrm{Fe}^{2+}$ ) over time. The aqueous $\mathrm{Fe}^{2+}$ was initially enriched with ${ }^{57} \mathrm{Fe}\left(\delta^{57 / 56} \mathrm{Fe}=840.43 \%\right.$ ), while the goethite was isotopicallynormal $\left(\delta^{57 / 56} \mathrm{Fe}=-0.12 \%\right)$. The gray line is the isotopic composition $\left(\delta^{57 / 56} \mathrm{Fe}=37.57 \%\right)$ that both phases would have if they reached isotopic equilibrium. Reactors contained $2 \mathrm{~g} / \mathrm{L}$ goethite buffered at $\mathrm{pH} 7.5,1 \mathrm{mM} \mathrm{Fe}{ }^{2+}, 25 \mathrm{mM} \mathrm{KBr}$, and $25 \mathrm{mM}$ HEPES buffer. The data were fit with the homogeneous (dashed lines) and heterogeneous models (solid lines) using the time-dependent equations described in Section 2.1, which were solved in a time-dependent manner using the Stella software package. The original data are from Environmental Science \& Technology, Vol. 43, R.M. Handler, B.L. Beard, C.M. Johnson, and M.M. Scherer. Atom Exchange between Aqueous Fe(II) and Goethite: An Fe Isotope Tracer Study. Pages 1102-1107. Copyright 2009, with permission from ACS Publications.

examine iron oxide recrystallization reactions in the presence of aqueous $\mathrm{Fe}^{2+}$ (Crosby et al., 2005; Pedersen et al., 2005), it was the first the show that such extensive recrystallization could occur without any major structural or morphological changes. This study sparked several subsequent studies focused on revealing if and how this process influenced trace metal mobility

In a subsequent study (Joshi and Gorski, 2016), the authors observed detectable, albeit subtle, changes to goethite particle dimensions when nano-particulate goethite was reacted with aqueous $\mathrm{Fe}^{2+}$ under conditions similar to those used in the Handler et al. (2009) study. By measuring the lengths and widths of hundreds of goethite particles over time and statistically analyzing their mean and median dimensions, the authors found that the particle dimensions changed dynamically over time, which could be explained by aqueous $\mathrm{Fe}^{2+}$ preferentially adsorbing to the particle edges and reductive dissolution of structural $\mathrm{Fe}^{3+}$ occurring 

for a potential driving force this recrystallization reaction.
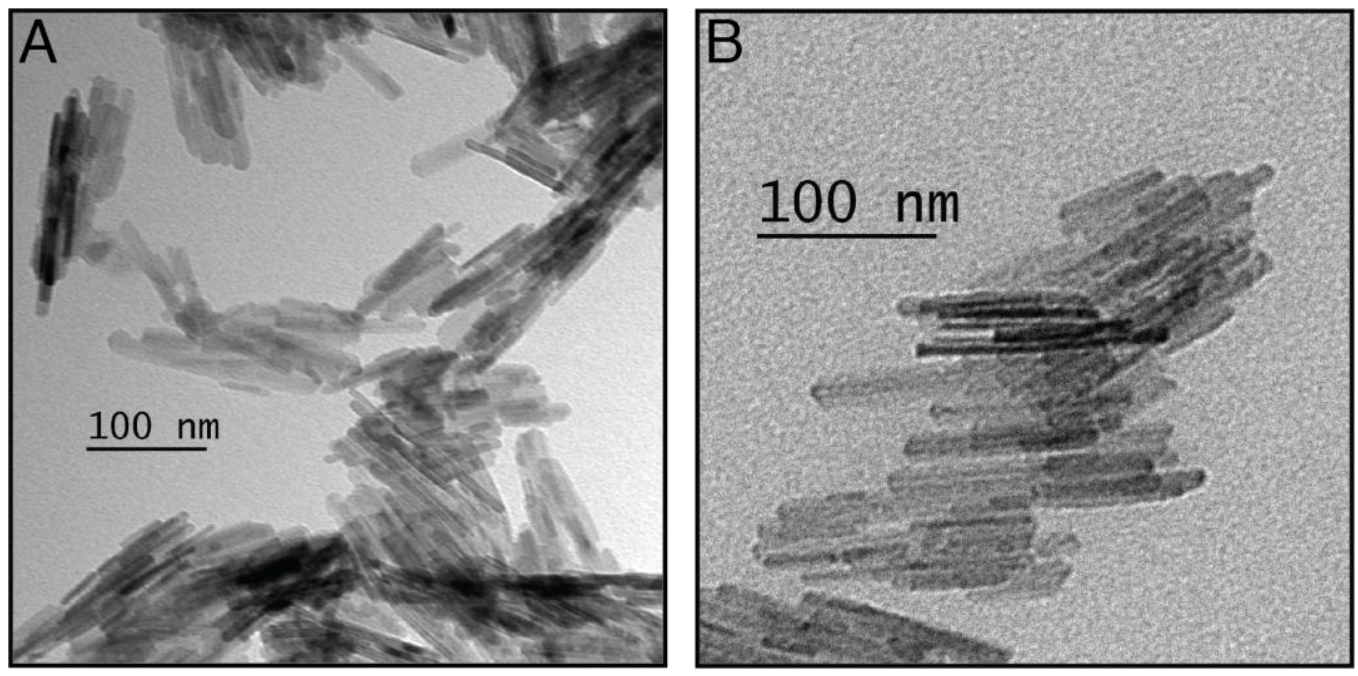

Figure 7. Transmission electron microscopy (TEM) images of nanoparticulate goethite after mixing in buffer for 30 days without $(\mathrm{A})$ and with $(\mathrm{B})$ aqueous $\mathrm{Fe}^{2+}$. Data from Environmental Science \& Technology, Vol. 43, R.M. Handler, B.L. Beard, C.M. Johnson, and M.M. Scherer. Atom Exchange between Aqueous Fe(II) and Goethite: An Fe Isotope Tracer Study. Pages 1102-1107. Copyright 2009, with permission from ACS Publications.

To further understand the process by which stable mineral recrystallization occurred in the Handler et al. (2009) study, we fit the data using the homogeneous and heterogeneous models presented in Section 2.1 (Figure 6). In each scenario, the dissolution and precipitation fluxes were assumed to be equal to each other, while the overall recrystallization rate was parameterized as a function of the reservoir mass at any given time (i.e., $\%$ per time). The most apparent difference between the two models is in the $\delta^{57 / 56} \mathrm{Fe}$ values of aqueous $\mathrm{Fe}^{2+}$. While the homogeneous model accurately fits the entire temporal trend, the heterogeneous model does not. This inability of the heterogeneous model to fit the data arises from the fact that the model assumes that no back reaction occurs between the recrystallized solid and aqueous $\mathrm{Fe}^{2+}$; thus, in the heterogeneous model, the only flux that impacts aqueous $\mathrm{Fe}^{2+}$ is the dissolution of the unexchanged solid (i.e., $\delta^{57 / 56} \mathrm{Fe}=-0.12 \%$ ). Because the solid:fluid mass ratio is high, ranging between 21 and 40 over the course of the experiment, this is the main driver of the aqueous $\mathrm{Fe}^{2+}$ trend over time. Interestingly, the fact that the ${ }^{57 / 56} \mathrm{Fe}$ of aqueous $\mathrm{Fe}^{2+}$ approaches that of the 
bulk solid implies that at least part of the recrystallized fraction of the solid continues to react with the aqueous phase over the course of the experiment.

The fact that the homogenous model can be used to accurately fit the Handler et al. (2009) data does not, however, prove that the homogeneous model is an accurate physical description of the recrystallization reaction. When fitting data with the homogeneous model, one assumes that the entire recrystallized fraction of the $\mathrm{Fe}^{3+}$ in the solid is an isotopic equilibrium with the aqueous $\mathrm{Fe}^{2+}$ (and that the fraction of the solid that has not recrystallized has the same isotopic composition as the original goethite). This assumption can be indirectly tested for the dataset in Figure 6 using complementary data presented by Handler et al. in a subsequent study in which the authors presented sequential chemical extraction data for different pools of Fe associated with the goethite over the course of the recrystallization reaction (Figure 4 in Handler et al., 2014). The data clearly show that the $\delta^{57 / 56} \mathrm{Fe}$ values of solidassociated Fe in each extraction pool differ at all time points: more easily extractable solid has $\delta^{57 / 56} \mathrm{Fe}$ values closer, but not identical, to that of aqueous $\mathrm{Fe}^{2+}$. This contradiction between the extraction data and the underlying assumption in the homogenous model implies either that (1) the model is an inaccurate descriptor of the recrystallization mechanism or (2) the extracts each contained mixtures of recrystallized and pristine goethite. If the latter were true, it would imply that the solid is being randomly sampled during the extractions, which could be the case if recrystallization does not affect or is not affected by the relative solubility of different portions of the solid. Clearly, there is insufficient data to differentiate between these possibilities. We raise this point not to challenge the use of the homogeneous model to fit the data and calculate and extent of recrystallization, but rather to point out that (1) even if a model accurately fits experimental data, it does not necessarily mean it is an accurate physical description of the recrystallization process; and (2) there are real challenges in linking bulk isotopic changes in the solid and aqueous phase to other measurements, such as sequential chemical extractions. More generally, this example highlights the difficulties in selecting, validating, and justifying the appropriate model used to interpret data and ultimately calculate rates and extents of recrystallization. 
Redox-active stable mineral recrystallization of iron oxides has been shown to impact trace metal cycling in experimental systems through multiple reaction pathways. Spectroscopic approaches have shown that aqueous trace metals (e.g., $\mathrm{Ni}^{2+}$ ) can become structurally incorporated into oxides during recrystallization (Frierdich et al., 2011; Frierdich and Catalano, 2012a, b; Latta et al., 2012b; Hinkle and Catalano, 2015). Such techniques can distinguish between adsorbed and structurally bound metals, which is important given that many metals will adsorb to iron oxides in the absence of $\mathrm{Fe}^{2+}$ (e.g., Jenne, 1968; Coughlin and Stone, 1995).

Redox-active recrystallization in the presence of aqueous $\mathrm{Fe}^{2+}$ also appears to promote iron oxide dissolution and precipitation and subsequent release of occluded trace metals, which does not occur in the absence of aqueous $\mathrm{Fe}^{2+}$ at circumneutral $\mathrm{pH}$ values (Frierdich et al., 2011; Frierdich and Catalano, 2012a, b; Frierdich et al., 2012; Latta et al., 2012b; Hinkle and Catalano, 2015). The extent to which trace metal release occurs depends largely on the trace metal's atomic size and whether or not the metal is redox-active. Redox-inactive metals (e.g., Ni) appear to be released passively during recrystallization (Frierdich et al., 2014a), while redox-active metals (e.g., Mn) may actively influence the recrystallization reaction (Frierdich and Catalano, 2012b). For example, the ionic radius of $\mathrm{Mn}^{3+}$ is similar to that of $\mathrm{Fe}^{3+}$, while $\mathrm{Mn}^{2+}$ is approximately $0.2 \AA$ larger than $\mathrm{Fe}^{3+}$. Thus, reducing structural $\mathrm{Mn}^{3+}$ to $\mathrm{Mn}^{2+}$ may destabilize the mineral structure, promoting recrystallization (Frierdich and Catalano, 2012b). As with goethite, the redox-active recrystallization of hematite and magnetite can also lead to trace metal release and incorporation (Frierdich et al., 2011; Frierdich and Catalano, 2012a, b; Gorski et al., 2012; Latta et al., 2012b).

It is very likely the crystallinity of the oxide plays an important role in the recrystallization reaction. Frierdich et al. (2014a) compared the extent of recrystallization at $\mathrm{pH}$ 7.5 between two goethite batches using identical experimental conditions and syntheses, except that one batch was heated at $70^{\circ} \mathrm{C}$ for 14 days (i.e., "coarsened goethite"), while the other was only heated for 2.5 days (i.e., "fresh goethite"). Under otherwise identical experimental conditions, the coarsened goethite reacted marginally in the presence of $\mathrm{Fe}^{2+}$ for 30 days $(\mathrm{F}=$ 0.20, fractional approach model) compared to the fresh goethite $(F=0.96$, fractional approach model). While the specific surface areas of these samples differed (i.e., coarsened: $13 \mathrm{~m}^{2} / \mathrm{g}$, fresh: 
$40 \mathrm{~m}^{2} / \mathrm{g}$ ), the variation in surface area is likely not the sole explanation for the difference in reactivities. In another study conducted under the same solution conditions, recrystallization rates for $40 \mathrm{~m}^{2} / \mathrm{g}$ and $110 \mathrm{~m}^{2} / \mathrm{g}$ goethite samples were very similar, which was attributed to goethite undergoing extensive aggregation at this $\mathrm{pH}$, thus suggesting the specific surface areas of powders may not be representative of the reactive surface area when suspended in solution (Reddy et al., 2015). Currently, it is mechanistically unclear how crystallinity affects recrystallization. The differences in crystallinity likely manifest in different abundances of surface and bulk crystalline defects, although such defects have been difficult to directly observe. If such defects are present and they do relate to recrystallization extents, it would indicate that redox-active goethite recrystallization may be driven by the removal of imperfections, as discussed below.

Redox-active goethite recrystallization also depends strongly on solution $\mathrm{pH}$, with more extensive exchange occurring at higher $\mathrm{pH}$ values. At $\mathrm{pH} 7.5$, Reddy et al. (2015) observed extensive goethite recrystallization (68\%, homogenous model) after 122 days. By contrast, at $\mathrm{pH}$ 6.5 the same goethite recrystallized less extensively (17-25\%, homogenous model). The extent of goethite recrystallization was even lower at more acidic pHs, consistent with the results of (Handler et al., 2014). Reddy et al. (2015) hypothesized that the rate of recrystallization depends on the amount of goethite-associated or "sorbed" $\mathrm{Fe}^{2+}$, which is larger at higher $\mathrm{pH}$ values. The basis for this hypothesis is that more goethite-associated $\mathrm{Fe}^{2+}$ leads to more interfacial electron transfer events, which are ultimately assumed to control recrystallization rate. Note that the results cannot be explained by a change in the aqueous complexation of $\mathrm{Fe}^{2+}$ as a function of $\mathrm{pH}$, as $\mathrm{Fe}^{2+}$ is predominantly present as free $\mathrm{Fe}^{2+}(>90 \%)$ below $\mathrm{pH} 8.4\left(\mathrm{Fe}^{2+}+\mathrm{OH}^{-}=\mathrm{FeOH}^{+}, \log \left(\mathrm{K}_{1}\right)=\right.$ 4.6) (Stumm and Morgan, 1970). These results suggest that the amount of $\mathrm{Fe}^{2+}$ associated with the oxide may prove to be an important parameter when attempting to develop kinetic-based models that estimate redox-active stable mineral recrystallization rates.

In addition to goethite, redox-active recrystallization has also been documented to occur in hematite (Frierdich et al., 2015b), magnetite (Gorski et al., 2012; Frierdich et al., 2014b), and Sistabilized ferrihydrite (Jones et al., 2009; Wu et al., 2011; Wu et al., 2012). Generally, these oxides recrystallize to a lesser extent than goethite. The origin for these differences cannot be ascribed 
to solution conditions or the amount of $\mathrm{Fe}^{2+}$ that is taken up by the solid, and therefore they are most likely due to structural differences among the oxides. Approximately $10 \%$ of structural Fe in magnetite has been found to recrystallize at circumneutral $\mathrm{pH}$ [original data in (Gorski et al., 2012; Frierdich et al., 2014b), modeled using the homogeneous model in (Handler et al., 2014)]. This suggests that only $\mathrm{Fe}$ atoms relatively close to the magnetite surface participate in the recrystallization reaction. Using a ${ }^{57} \mathrm{Fe}$ Mössbauer isotope tracer technique, Gorski et al. (2012) found no evidence for preferential reaction of either the octahedral or tetrahedral Fe in magnetite. Hematite recrystallization was initially thought to involve surface Fe atoms only based on calculated recrystallization extents and surface area measurements (Pedersen et al., 2005), but more recent work has shown that hematite can extensively recrystallize (up to $40 \%$, homogenous model) (Frierdich et al., 2015b). The apparent disagreement between these two studies can most likely be explained by differences in the experimental parameters used. The hematite used in by Frierdich et al. (2015b) had a higher specific surface area $\left(54 \mathrm{~m}^{2} / \mathrm{g}\right)$ than the hematite used by Pedersen et al. (2005) $\left(19 \mathrm{~m}^{2} / \mathrm{g}\right)$. Additionally, the solution $\mathrm{pH}$, aqueous $\mathrm{Fe}^{2+}$ concentrations, and hematite concentrations differed. Frierdich et al. (2015b) observed that the extent of hematite recrystallization depend strongly on the solution $\mathrm{pH}$, with more extensive recrystallization occurring at higher $\mathrm{pH}$ values.

The studies conducted to date have provided important insights into the extents to which redox-active recrystallization occurs in laboratory experiments and how both mineralogical and solution properties affect the reaction. However, there are still basic questions regarding the recrystallization mechanism that remain unresolved. For example, Frierdich et al. (2015a) simultaneously used Fe and O isotopes to track goethite recrystallization in the presence of aqueous $\mathrm{Fe}^{2+}$. They found significant disagreement between the calculated recrystallization extents using the two elements, and their calculations indicated that the fraction of the pool of Fe atoms in the solid that exchanged was three times larger than the fraction of the $\mathrm{O}$ atoms in the solid that exchanged, using the homogeneous model. The authors proposed that this observation could be explained by $\mathrm{O}$ and $\mathrm{Fe}$ atoms having different binding affinities in the solid or elemental differences in diffusive fluxes within the goethite lattice. This 
surprising and puzzling result illustrates the challenges in elucidating a mechanistic model that can accurately describe observations.

The lack of a mechanistic understanding of redox-active, as well as redox-inactive, stable mineral recrystallization in laboratory studies presents obvious challenges when attempting to translate observations directly to natural systems. Extrapolating observations made on the order of months to years to geological time scales is not straightforward. Regardless, it is important to realize that even if stable mineral recrystallization occurs over relatively short time scales (i.e., months to years) then ceases, it is still relevant to natural systems. If mineral archives used as proxies undergo rapid recrystallization in natural systems, then the recorded isotopic and elemental compositions would (at least to some extent) reflect post-formational and/or postdepositional environments and not solely the conditions under which the mineral formed. Similarly, short-term recrystallization would affect the fate of trace metals, toxic elements, and radionuclides in engineered and natural environmental systems. In the next section, we discuss the potential for stable mineral recrystallization to occur in low temperature environmental and geological systems.

\section{POTENTIAL FOR STABLE MINERAL RECRYSTALLIZATION IN NATURAL SYSTEMS}

What makes the recent observations of stable mineral recrystallization in the laboratory so intriguing is the possibility that the same type of reactions may occur in natural systems over a range of time scales. If stable mineral recrystallization occurs in the environment, the implications with respect to interpreting and understanding diagenetic alteration of geological proxies would be manifold. Most importantly, stable mineral recrystallization, as it is currently understood, does not produce clear morphological evidence of post-formational changes over short time scales (i.e., evidence at the macroscale). Further, stable mineral recrystallization in natural systems may impact the time scale over which geoscientists consider diagenetic effects to be important. One relevant example is the alteration that may occur in biogenic carbonates as they settle through the water column, a process that is comparable to that of laboratory experiments in many ways. The time scale of settling occurs over weeks to months in water chemistries that are close, although not necessarily at, calcite saturation. Therefore stable 
mineral recrystallization may be relevant to so-called "core-top" and even sediment trap proxy calibrations (e.g., Dekens et al., 2002; Anand et al., 2003). Collectively, these implications could be important for understanding and interpreting the geochemical information preserved in minerals found in rocks and sediments.

The potential for mineral recrystallization to affect the interpretation of the elemental and isotopic geochemistry of rocks and sediments (i.e., the rock record) has been recognized for decades (i.e., since the inception of oxygen isotope thermometry) (e.g., Epstein et al., 1951; Urey et al., 1951). There is a substantial amount of evidence demonstrating that recrystallization can occur during deposition and diagenesis, particularly with regard to marine biogenic carbonates (e.g., Richter and DePaolo, 1987; Richter and DePaolo, 1988; Delaney, 1989; Richter and Liang, 1993; Schrag et al., 1995; McManus et al., 1998; McGregor and Gagan, 2003; Sexton et al., 2006; Fantle et al., 2010). In many cases, however, such recrystallization was coupled, or thought to be coupled, to overt mineralogical and/or morphological changes over million-year time scales. Note that in the discussion that follows, we utilize the more general term "recrystallization" as opposed to "stable mineral recrystallization"; we adopt the definition of recrystallization proposed by Folk (1965), according to which recrystallization refers to a process in which a mineral's trace element concentrations, crystal volume, lattice orientation, and/or morphology change, but the mineralogy is unchanged (e.g., calcite remains calcite). Accordingly, the term "stable mineral recrystallization" refers to a process that is included in those processes that Folk would classify as "recrystallization".

As a consequence of these observations, it is necessary to state explicitly that recrystallization can, and often is, linked to changes in the mineral, and that such recrystallization is a critically important process that occurs after mineral formation. The purpose of this discussion is not to debate this point, but to entertain the possibility that recrystallization could occur over geologically relevant time scales in natural systems without generating overt changes in the mineral. As is discussed throughout this review, classifying a change as "overt" is a critical, although highly subjective, aspect of this discussion since the resolution and precision of available techniques vary. In other words, the lack of overt changes cannot be used to imply that the mineral does not react with its environment. 
In natural systems, stable mineral recrystallization may be particularly relevant over short time scales $(\ll<1 \mathrm{Ma})$, over which minerals are often considered to be less susceptible to alteration. In addition, stable mineral recrystallization potentially provides a means to keep mineral systems open to exchange over very long time scales, which challenges assumptions that elemental and isotopic alteration (1) only occurs early in the sedimentary history of a solid (e.g., Baker et al., 1982; Rudnicki et al., 2001; Edgar et al., 2013) and (2) is always accompanied by overt changes in mineralogy, macro-/microstructure, and/or morphology.

Determining if stable mineral recrystallization occurs in geological systems and distinguishing it from other recrystallization mechanisms is obviously difficult, given the fact that the time scale over which post-depositional alteration occurs in natural systems is on the order of thousands to millions of years, which is several orders of magnitude larger than that interrogated in laboratory studies. Additionally, multiple significant challenges relate to identifying how the minerals change over time. Such identification is complicated by difficulties characterizing the original, pristine mineral in natural systems. Often, this must be inferred based on assumptions (e.g., that carbonates in clay layers are better preserved than those in carbonate-rich sediments over time; (Sexton et al., 2006)). Specifically with regard to biogenic carbonates, microstructural features can vary within a given population (e.g., foraminiferal tests), such that identifying an "initial" state for a given specimen is highly uncertain. Moreover, there can be chemical and isotopic variability in specimens at the nanometer scale - as discussed earlier - that is analytically challenging to interrogate with precision, particularly when probing isotopic composition at the sub-permil level.

Thus, it is important to qualify our discussion of stable mineral recrystallization in natural systems. There is insufficient data to determine definitively if and when stable mineral recrystallization, as it is understood on the basis of experimental observations, occurs in natural systems. In this contribution, therefore, we review existing literature and discuss the implications that stable mineral recrystallization may have for the interpretation of proxy-based records of the past. 


\subsection{Field-based data collection}

Quantifying solid-fluid exchange rates from field data is a complicated endeavor for a multitude of reasons, regardless of the mechanism involved. First, recrystallization in natural systems generally occurs at slower rates than in laboratory experiments, so multiple observations in time are not practical for constraining rate. Further, given the cost and effort associated with sampling in deep time (often by drilling deep cores on land or in the ocean), sites are rarely revisited multiple times. Second, meaningful constraints on rates require measurements of both the solid and coexisting aqueous phase for a sample, as well as the interaction time. While collecting solids in drill cores or outcrops is relatively simple, collecting a representative fluid - that is, one that chemically reflects interaction with the sampled solid - is often times less straightforward. Fluids can be transported relative to the solids, especially in fluid unsaturated systems (e.g., the vadose zone), such that the fluid captured at any instant is not necessarily representative of interaction with the local solid. In addition, water chemistry can vary temporally and spatially, yet its collection is often limited in its temporal and spatial scope. To minimize the impacts of this issue, it is useful to work in systems in which the solid chemistry is relatively homogeneous or, at the very least, well characterized. Finally, even in such well-characterized systems, determining the reaction time between fluid and solid can be highly uncertain.

One of the more constrained systems in which to study recrystallization on Earth is the marine sedimentary column, which is fluid saturated, has relatively well-constrained boundary conditions, and is sampled in a routine and reproducible manner. Marine sediments have been regularly sampled by ocean drilling programs for several decades (e.g., the Deep-Sea, Ocean, and Integrated Ocean Drilling Programs have operated continuously between 1966 and 2013), providing comprehensive basic geochemical and geophysical data, snapshots of pore fluid chemistry, and micropaleontological data that can be used to interpret time. Onboard geochemical analyses of the elemental composition of pore fluids squeezed from the core are routinely performed, and samples obtained through the drilling program can be characterized isotopically on-shore. Using these data to study recrystallization requires additional interpretation. For example, solute transport via diffusion and advection must be simulated, 
and sedimentation rates estimated from magneto- and biostratigraphy (see Fantle et al. (2010) for summary of approaches at quantifying rates in such settings). The fluid and solid elemental and isotopic compositions can then be used to quantify post-depositional recrystallization.

\subsection{Observations from marine sedimentary systems}

Isotopic and elemental geochemical data collected in marine sedimentary systems have yielded compelling evidence indicating that recrystallization (though not necessarily stable mineral recrystallization) occurs at or near chemical equilibrium, particularly in carbonate-rich sediments. Recrystallization affects the geochemistry of carbonate minerals, including $\mathrm{Sr}$ concentration and isotopic composition $\left({ }^{87} \mathrm{Sr} /{ }^{86} \mathrm{Sr}\right.$ ratio) (e.g., Richter and DePaolo, 1987; Richter and DePaolo, 1988; Richter and Liang, 1993; Fantle and DePaolo, 2006; Fantle, 2010; Fantle, 2015), oxygen isotopic composition ( $\left.\delta^{18} \mathrm{O}\right)$ (Killingley, 1983; Schrag et al., 1995; Fantle, 2015), and Mg/Ca ratio (Baker et al., 1982; Fantle and DePaolo, 2007; Fantle et al., 2010). The latter two parameters are particularly important because they are used as paleotemperature proxies to infer the spatial and temporal evolution of Earth's past climate. Both identifying and quantifying the rates and extent of diagenetic recrystallization are critical, especially because proxies that occur at trace concentrations $(<\mathrm{ppm})$ in marine carbonates, such as $\delta^{11} \mathrm{~B}$ and $\mathrm{B} / \mathrm{Ca}$ (paleo-pH proxies), are highly susceptible to post-formational alteration. Recognizing and properly accounting for recrystallization has proven to be a data- and time-intensive activity that requires thorough geochemical characterization, with quantitative constraints provided by numerical modeling of the system.

Observations of interactions between biogenic marine carbonates (specifically foraminiferal tests and nannofossils) and interstitial pore fluids were first made more than forty years ago (e.g., Wise, 1973; Sayles and Manheim, 1975; Sayles, 1979, 1981; Baker et al., 1982; Killingley, 1983), though general studies of marine pore fluids extend back even further (Murray and Irvine, 1893) (for a more exhaustive compilation of earlier work, see Manheim, 1976). In the case of biogenic carbonates, the primary indicator of recrystallization is the characteristic increase in pore fluid Sr concentrations with depth in the sedimentary column (Figure 8a) (Sayles and Manheim, 1975). Strontium is a good chemical indicator of fluid-solid 
a

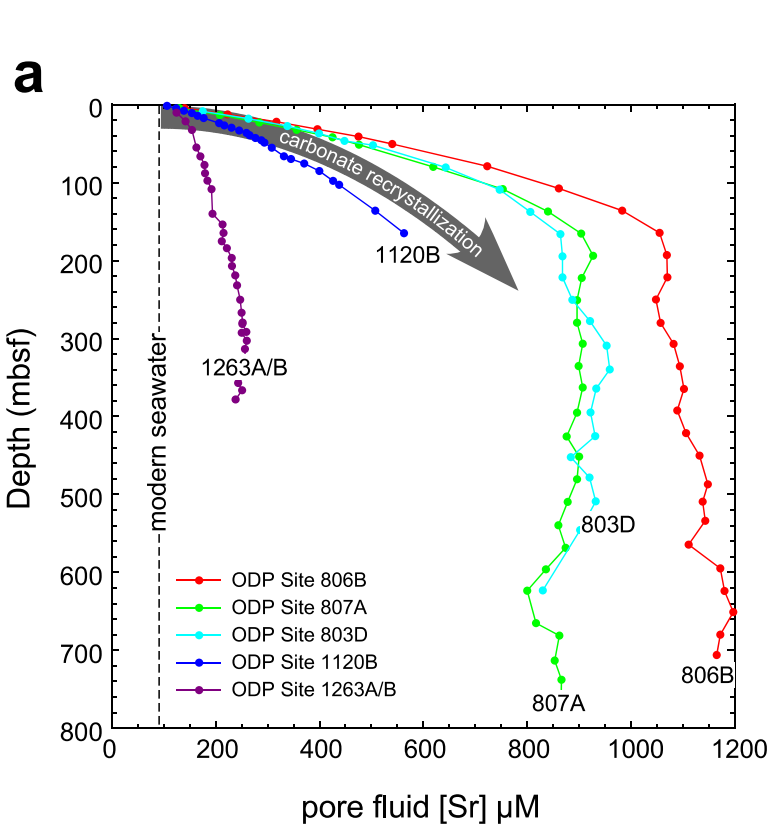

interactions in such settings because its concentration in biogenic carbonates is higher than the equilibrium concentration in abiotic carbonates (Manheim and Sayles, 1971). Thus, during fluidmineral interactions, $\mathrm{Sr}$ is preferentially partitioned into the pore fluid. Because the disparity between biotic and abiotic Sr partitioning is significant, Sr concentration profiles with depth are not at a diffusive steady-state over hundreds of meter length scales; therefore, $\mathrm{Sr}$ is an ideal indicator of active reaction over long time scales (Fantle et al., 2010).

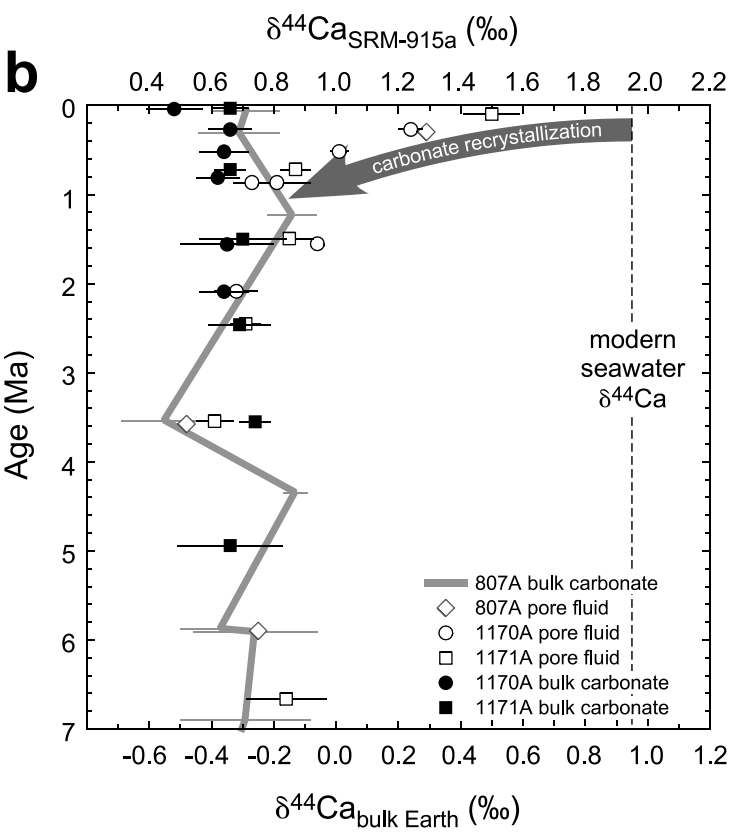

Figure 8. (a) Pore fluid Sr concentration $(\mu \mathrm{M})$ profiles at five Ocean Drilling Program (ODP) sites that have carbonate-rich sediments (generally $>>80 \% \mathrm{CaCO}_{3}$ ). (b) Calcium isotopic composition $\left(\delta^{44} \mathrm{Ca}\right)$ of pore fluids and bulk carbonate at three ODP sites. Pore fluid Sr concentrations: ODP JANUS database [http://iodp.tamu.edu/janusweb/links/links_all.shtml]. Calcium isotope data: (Fantle and DePaolo, 2007; Fantle, 2015)

996

Post-depositional reaction rates between pore fluids and bulk carbonate sediments have been quantified mainly using simple reactive transport models to simulate pore fluid $\mathrm{Sr}$ concentration and Sr isotopic $\left({ }^{87} \mathrm{Sr} /{ }^{86} \mathrm{Sr}\right.$ ) data (Richter and DePaolo, 1987; Richter and DePaolo, 1988; Richter and Liang, 1993; Richter, 1996; Fantle and DePaolo, 2006; Fantle et al., 2010; Fantle, 2015). Strontium isotopes are critical tools in such work because Sr concentrations can reach steady state over length scales of $~ 150$ meters (and therefore offer at best only minimum rates of recrystallization below this depth). Interestingly, the attainment of steady state with respect to pore fluid Sr concentrations has been interpreted as indicating a cessation of recrystallization at 
relatively shallow depths (e.g., Baker et al., 1982). However, Sr isotopes do not necessarily reach steady state below this depth and can therefore be used to constrain reaction rates over larger length (and thus time) scales (Fantle and DePaolo, 2006). Consequently, Sr isotope data strongly support the existence of sustained, albeit slow, fluid-mineral interactions between carbonates and pore fluids over tens of millions of years.

The Sr concentration and isotopic evidence for exchange has been complimented by recent $\mathrm{Ca}$ isotopic $\left(\delta^{44} \mathrm{Ca}\right)$ analyses in carbonate-rich sedimentary systems (Figure 8b) (e.g., Fantle and DePaolo, 2007; Fantle, 2015). The Ca isotopic data clearly demonstrate that pore fluid

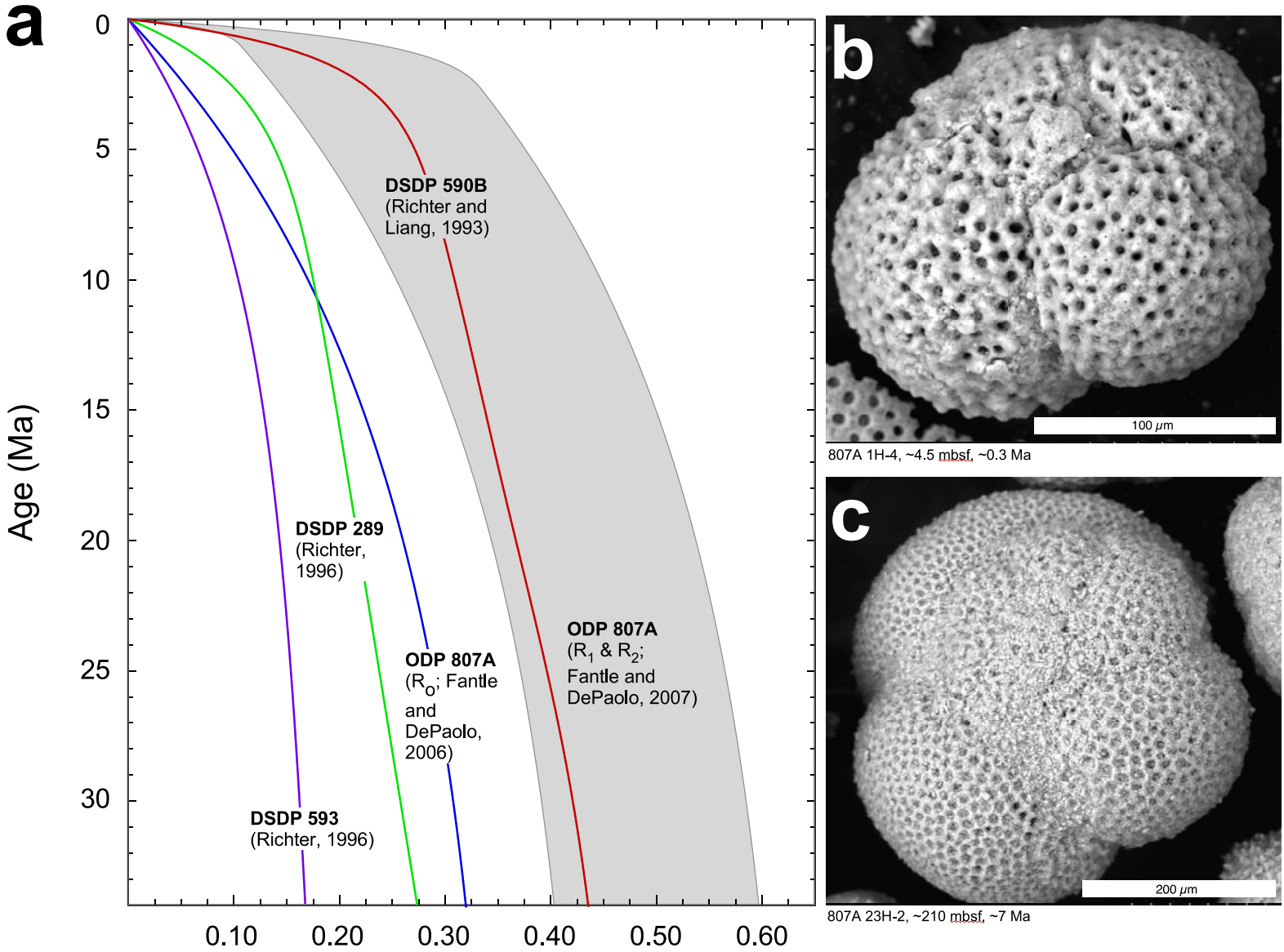

Fraction of bulk sediment recrystallized

Figure 9. (a) Integrated fraction of bulk carbonate sediment recrystallized, given recrystallization rates as a $f($ age $)$ constrained by various studies. The gray shaded region indicates the range of rates that are inferred from $\mathrm{Ca}$ isotopes (denoted $\mathrm{R}_{1}$ and $\mathrm{R}_{2}$ ), compared to $\mathrm{Sr}$ geochemistry $\left(\mathrm{R}_{0}\right)$, at ODP Site 807, Hole A. Backscattered electron scanning electron microscopy images of foraminiferal tests at ODP Site 807 , Hole A from (a) $\sim 4.5$ mbsf (meters below seafloor) and (b) $\sim 210 \mathrm{mbsf}$, the length scale over which pore fluid $\mathrm{Sr}$ concentrations increase by a factor of ten relative to seawater. 
$\delta^{44} \mathrm{Ca}$ evolves from the seawater value $\left(\sim 1.9 \%\right.$ o) towards the $\delta^{44} \mathrm{Ca}$ of the solid $(\sim 0.6 \%$ o $)$ over $\sim 1$ Ma time scale. Simple mass balance arguments, in addition to more involved numerical modeling approaches, indicate that this trend is not simply due to carbonate dissolution but reflects recrystallization (Fantle and DePaolo, 2006; Fantle et al., 2010). Further, there have even been suggestions, based not only on $\mathrm{Ca}$ isotopes but also on $\mathrm{U}$ isotopes, that the recrystallization rates of young (i.e., <1 Ma) carbonates in both carbonate-rich and siliciclastic sections are significantly higher than those constrained by Sr geochemistry (Maher et al., 2004; Fantle and DePaolo, 2007; Fantle, 2015). This observation is important, as it suggests pervasive reaction in carbonate sediments that can impact a variety of geochemical proxies (Figure 9).

A key assumption that must be made in these modeling efforts is whether or not the rate of fluid-mineral interactions changes over as a function of either depth or age. Such an assumption is important for predictions of proxy alteration in sections that experience hiatuses in deposition and can impact comparisons between sites that have different sedimentation rates. Generally, the rate is assumed to slow with depth to fit data properly, as relatively rapid change is observed in shallow pore fluid $\delta^{44} \mathrm{C}$ and Sr concentrations, while lower rates are inferred at deeper depths from pore fluid ${ }^{87} \mathrm{Sr} /{ }^{86} \mathrm{Sr}$. In marine sediments, it is difficult to decipher whether depth or age control the variation in rate, given that the two are almost linearly related. It is reasonable, given the manner in which carbonates likely react in the column (Reeves and Rothman, 2013), to assert that age or time is the appropriate parameter. Age dependence is also inferred for weathering silicates in marine and terrestrial systems (as summarized in Figure 11 in Maher et al., 2004). The observations that fluid-mineral interactions rates slow with time are wholly consistent with the experimental data collected for stable mineral recrystallization in laboratory studies, although the time scales in natural systems are several orders of magnitude larger than in experimental studies.

\subsection{The potential significance of stable mineral recrystallization in marine carbonates}

Based on the observations summarized above, it is virtually impossible to determine if stable mineral recrystallization, as defined in this review, occurs in marine carbonates. What can be said, however, is that the spatial scale of observation is extremely important when making 
this determination. From a macroscopic perspective, for instance, recrystallization of marine carbonates does not necessarily generate overt structural or morphological changes. In fact, it has been observed that morphological/mineralogical indicators of recrystallization are "impossible to see directly under the binocular microscope" (i.e., at one scale of observation; (Sexton et al., 2006)). Further, while there are clearly cases in the marine sedimentary column where cementation and euhedral calcite formation occur, thereby markedly changing the morphology of biogenic carbonates, it is also commonly observed that biogenic $\mathrm{CaCO}_{3}$ tests generally retain their gross morphology over long time scales, even in situations where recrystallization is geochemically recognizable. At ODP Site 807A, for instance, a substantial fraction of bulk carbonates ( $10-60 \%)$ was determined to have recrystallized over tens of millions of years (Figure 9a) (Fantle and DePaolo, 2006; Fantle and DePaolo, 2007). When foraminiferal tests collected at $\sim 4.5$ mbsf (meters below seafloor) and 210 mbsf were analyzed using scanning electron microscopy (Figure $\mathbf{9 b}$-c), the images revealed no observable differences in the gross features of the tests, suggesting the possibility that stable mineral recrystallization could be occurring.

While there is not necessarily macro-scale evidence of recrystallization in natural systems, such as the sedimentary column, there have been suggestions based on micro-scale observations that the recrystallization of foraminiferal tests is coupled to morphological changes. One example is the "glassy to frosty transition" that has been documented to change the appearance of foraminiferal tests at the microscale (Sexton et al., 2006). This process has been described as involving "micron-scale cemented overgrowths" and perhaps "neomorphism" ["recrystallization" by Folk's (1965) definition] of primary biogenic calcite. Sexton et al. (2006) also mention that foramineral tests "altered in this manner commonly retain microstructural features such as wall pores and surface ornamentation" [e.g., Figure 7 in (Sexton et al., 2006)]. Ostensibly, then, there are similarities between stable mineral recrystallization as we define it and the process occurring in marine sediments, specifically the resilience of small-scale microstructure.

Additionally, there is a significant body of research that demonstrates that some foraminiferal tests are chemically heterogeneous (e.g., Eggins et al., 2003; Eggins et al., 2004; 
Sadekov et al., 2005). One intriguing possibility is that it is precisely this small-scale chemical heterogeneity that drives recrystallization in natural systems. It has, for instance, been shown that the solubility of low-Mg calcite is higher than that of pure calcite (Berner, 1975). As we discuss in the next section, small-scale chemical heterogeneities, including defects, could serve as the driving force for stable mineral recrystallization (Curti et al., 2010; Latta et al., 2012b; Avrahamov et al., 2013; Heberling et al., 2014; Joshi and Gorski, 2016). With regard to the driving force, then, the recrystallization of biogenic carbonates in natural systems may also be comparable to stable mineral recrystallization in the laboratory.

Ultimately, the work on carbonate recrystallization in marine sediments done to date indicates that a substantial fraction of carbonate sediment can react over tens of million of year time scales. Further, it is clear that foraminiferal tests are recognizable for what they are in many cases for tens of millions of years following deposition; though noticeably overprinted at the microscale, they are not obliterated. And though there remain open questions regarding mechanism and the manner in which bulk chemical changes are distributed within the heterogeneous sediment, there is a possibility that stable mineral recrystallization occurs in such settings. In fact, it may even be that stable mineral recrystallization is just as likely to occur in the water column as in the sedimentary column, which not only impacts the proxy record directly but also empirical core-top calibrations and observations that are used to decipher that record.

While stable mineral recrystallization is not the only process that could alter carbonate chemistry in the marine environment, its potential presence has important ramifications for the manner in which we explore the past. This is because the common assumption made in proxybased studies is that it is possible to separate (physically and/or chemically) low fidelity reacted material from high fidelity unreacted material. This assumption is complicated if stable mineral recrystallization occurs, and alters a sizeable fraction of a proxy archive, as its operation (seemingly) neither depends on nor generates distinct and separable phases.

Our discussion of stable mineral recrystallization and the difficulty with identifying its operation in natural systems raises the question: what is our expectation of the long-term expression of stable mineral recrystallization? As we have clearly stated throughout this review, 
the identification of stable mineral recrystallization is strongly influenced by short time scale laboratory observations, as well as how one defines "overt". Regarding the former, it may well turn out that the long time scale expression of stable mineral recrystallization is precisely what is observed in the sedimentary column (i.e., the presence of recognizable microscale features, albeit accompanied by features described as "overgrowths"). Relatedly, it be that the term "limited" is a better description of the expectations for changes in the mineral/test over long time scales, though deciding on a threshold dictating the application of "limited" to a given mineral can be just as subjective as gauging "overt" alteration. Finally, while stable mineral recrystallization may indeed operate slowly in natural settings, it could explain, we speculate, the rather continuous solid-fluid exchange that has been documented to occur over tens of millions of years in the sedimentary column.

\section{MeChANISTIC INSIGHTS REgARDING STABLE MINERAL RECRYSTALLIZATION}

Despite extensive observations of stable mineral recrystallization in low temperature aqueous experiments, the molecular-scale mechanism(s) by which this process occurs remains poorly understood. The primary reason for this lack of understanding is that stable mineral recrystallization occurs under apparent equilibrium conditions, in which the solution chemistry remains stable and the mineral does not appear to undergo any major morphological or structural changes. Thus, there is no overt indicator of a thermodynamic driving force. Of course, mineral dissolution and precipitation occur at the mineral surface when the system is at equilibrium, but this perpetual dissolution and precipitation cannot readily explain how atoms more than a few tens of nanometers deep in a mineral lattice are susceptible to interfacial exchange over relatively short time scales (e.g., Reeves and Rothman, 2013).

\subsection{Does stable mineral recrystallization result in detectable changes in minerals?}

Based on the findings discussed in Sections 2 and 3, we hypothesize that stable mineral recrystallization is in actuality accompanied by subtle changes in both mineral chemistry and morphology, which are difficult to detect with commonly employed spectroscopic and microscopic methods. Such changes could occur at the mineral surface, driven energetically via 
the removal of surface defects, a decrease in total surface area, or a decrease in the surface areas of specific, high energy crystalline faces (Curti et al., 2010; Avrahamov et al., 2013; Heberling et al., 2014). As explained below, this last possibility has previously been proposed to explain how stable mineral recrystallization occurs in redox-active minerals (Handler et al., 2009; Zarzycki et al., 2015a; Zarzycki et al., 2015b; Joshi and Gorski, 2016). The subtle changes in the mineral may involve the bulk mineral lattice, which initially contains structural defects, nanopores, and/or elemental impurities. For example, the presence of trace elements in the crystal lattice can alter the thermodynamic properties of the mineral and hence its solubility (e.g., Prieto, 2009). Spatial variations in relative mineral solubility, perhaps at the nanoscale, can then drive recrystallization. Relatedly, recent electron tomography studies has shown that synthetic iron oxides can contain nanopores that are more susceptible to reductive dissolution reactions, but are difficult to detect with commonly employed microscopic techniques (Echigo et al., 2012; Echigo et al., 2013).

Three lines of evidence support the hypothesis that minerals undergo subtle changes during stable mineral recrystallization in redox-inactive systems. The strongest line of evidence suggesting that minerals change during stable mineral recrystallization is that recrystallization rates slow over time, as evidenced by experiments using serial additions of tracer at different time points in redox-inactive systems (Mozeto et al., 1984; Avrahamov et al., 2013). Recrystallization rates have also been observed to slow over time in natural systems, as discussed above, but it is difficult to determine if this recrystallization is stable mineral recrystallization as defined here and described above. Because aqueous chemistry remained constant over the course of laboratory experiments, the decrease in reactivity must be attributed to a feature or characteristic of the solid that changes over time. To the best of our knowledge, no work has investigated if redox-inactive stable mineral recrystallization in the laboratory affects characteristics of the bulk mineral lattice, such as point, line, or plane defect concentrations, that could provide a thermodynamic driving force. Stable mineral recrystallization could also be driven by the removal of impurity defects, such as elemental substitutions in the crystal lattice, which is inferred to be a driver of the recrystallization of marine carbonates (e.g., the loss of Sr from biogenic carbonates). The lack of data to support 
such inferences is a result of the difficulty in detecting subtle changes in the elemental and isotopic compositions, as well as changes in defect concentrations, in small minerals at high spatial resolution.

The second line of evidence to support that minerals change during stable mineral recrystallization is that particle surfaces appear to become smoother based on scanning electron microscopy (SEM) images of calcite, gypsum, and barite collected at various experimental time points (e.g., Figure 5) (Curti et al., 2010; Avrahamov et al., 2013; Lestini et al., 2013) . Surface smoothing has been attributed to the hydration of surface sites and the annealing of microfractures and micro-cracks. Of course, this correlation should be interpreted cautiously, as it is unclear if the smoothing is directly related to stable mineral recrystallization or if it is an independent process that occurs concurrently.

The final line of evidence is that minerals change during recrystallization is less direct. Prior work has found that minerals with higher crystallinities (generated through aging prior to experiments) are relatively resistant to stable mineral recrystallization. Frierdich et al. (2014a) found that aging goethite at $70^{\circ} \mathrm{C}$ in water prior to reacting it with isotopically-labeled aqueous $\mathrm{Fe}^{2+}$ dramatically reduced the extent of recrystallization. As discussed above, it is unlikely that this reduction was due to differences in specific surface area. Instead, it is more likely that the aging decreased the density of surface and/or bulk defects and impurities. Identifying these changes using microscopic techniques, such as high-resolution transmission electron microscopy (HR-TEM) and scanning electron microscopy, is difficult. Prior work examining nano-particulate goethite before and after recrystallization in the presence of aqueous $\mathrm{Fe}^{2+}$ using HR-TEM and found no evidence of changes in surface topology, bulk crystallinity, aggregation behavior, or surface roughness associated with recrystallization (Handler et al., 2009; Handler et al., 2014; Joshi and Gorski, 2016) . These findings indicate that the changes that occur during stable mineral recrystallization may be extremely subtle and, thus, difficult to detect even using high resolution analytical tools. 


\subsection{Is stable mineral recrystallization driven by changes to specific crystalline faces?}

The driving force of stable mineral recrystallization is acknowledged to be a critical question, and it is one that has been addressed in several previous studies. Handler et al. (2009) initially hypothesized that the redox-active stable mineral recrystallization of goethite in the presence of aqueous $\mathrm{Fe}^{2+}$ involves the preferential growth of one crystal face coupled to loss of another crystal face, a mechanism termed the "redox-driven conveyor belt". In this case, the underlying driving force is hypothesized to be the minimization of Gibbs free energy that is accomplished by changing the proportion of various crystal faces in contact with solution via dissolution/precipitation (e.g., Yanina and Rosso, 2008; Zarzycki et al., 2015b). This hypothesis was predicated on earlier studies that showed interfacial electron transfer occurring in the presence of goethite and aqueous $\mathrm{Fe}^{2+}$, leading to oxidative goethite growth (Williams and Scherer, 2004; Silvester et al., 2005; Gorski and Scherer, 2011).

Based on these observations, Handler et al. (2009) suggested that redox-active stable mineral recrystallization involves three steps: (1) oxidative $\mathrm{Fe}^{2+}$ uptake and particle growth at a specific crystal face, (2) bulk electron conduction through the oxide lattice, and (3) reductive dissolution at other crystal faces. The hypothesis was supported by evidence for (1) preferential growth and dissolution of hematite in mildly acidic solutions hematite (Yanina and Rosso, 2008; Rosso et al., 2010), (2) potential gradients measured across the crystal faces of hematite (Yanina and Rosso, 2008; Rosso et al., 2010), and evidence of preferential growth of particles along their widths in the presence of aqueous $\mathrm{Fe}^{2+}$ (Joshi and Gorski, 2016).

The "redox-driven conveyor belt" mechanism is compelling in that it provides an explanation for how extensive redox-active stable mineral recrystallization can occur while only causing minor changes to the morphology of the mineral that may be difficult to detect (i.e., an increase and/or a decrease in the relative abundances specific crystalline faces). However, it remains unclear if this process is thermodynamically favorable. Bulk conduction through an oxide lattice has an energetic cost due to the oxide's electrical resistance; consequently, energy is lost as heat during conduction (Handler et al., 2014; Zarzycki et al., 2015b). If the energy lost to conduction is greater than the potential difference across the crystalline faces, the recrystallization process is thermodynamically unfavorable. Determining whether or not the 
energy balance works in favor of the conveyor belt mechanism is difficult to probe experimentally and will likely require insights from on-going $a b$ initio and molecular simulations (e.g., Zarzycki et al., 2015a; Zarzycki et al., 2015b).

\subsection{Does stable mineral recrystallization involve solid-state diffusion?}

Regardless of the driving force of stable mineral recrystallization, there is still a question as to how atoms initially deep within the mineral lattice exchange with atoms in solution. One possible explanation is that stable mineral recrystallization is controlled by solid-state atomic diffusion. This hypothesis is often dismissed in the literature because solid-state diffusion is thought to be too slow at room temperature to explain observed rates and extents of recrystallization. While this may be true in some cases, there is currently insufficient data in the literature to rule it out entirely because solid-state diffusion coefficients for atoms in minerals at low temperatures in aqueous environments are poorly constrained. A range of reasons explains such poor constraints, the most widespread being that they are often thought to be too slow to measure experimentally. An example of the uncertainty in existing constraints is the reported diffusion coefficients for $\mathrm{Fe}^{2+}$ in magnetite at room temperature and ambient pressure, which vary by 17 orders of magnitude: $10^{-3} \mathrm{~cm}^{2} \mathrm{~s}^{-1}$ (Gallagher et al., 1968), $10^{-12}-10^{-16} \mathrm{~cm}^{2} \mathrm{~s}^{-1}$ (White et al., 1994), $2.1 \times 10^{-15} \mathrm{~cm}^{2} \mathrm{~s}^{-1}$ (Sidhu et al., 1977), $1.3 \times 10^{-20} \mathrm{~cm}^{2} \mathrm{~s}^{-1}$ (Tang et al., 2003). Likewise, solidstate diffusion coefficients for calcite cited in stable mineral recrystallization studies vary between $10^{-20} \mathrm{~cm}^{2} / \mathrm{s}$ (Lahav and Bolt, 1964) at room temperature to $10^{-43} \mathrm{~cm}^{2} / \mathrm{s}$ at $100^{\circ} \mathrm{C}$ (Kronenberg et al., 1984).

While it is beyond the scope of this review to determine why such large discrepancies in solid-state diffusion coefficients exist, some insights can be provided. First, solid-state diffusion coefficients strongly depend on mineral structure and elemental composition (e.g., Fisler and Cygan, 1999). For example, trace elements incorporated into calcite increase the concentration of defects (e.g., Cygan et al., 2002), which are known to affect diffusion coefficients. Therefore a mineral such as calcite, which forms biogenically and with a range of trace element chemistries at the Earth's surface, likely cannot be described as having a single solid-state diffusion coefficient. 
Second, there are multiple mechanisms by which atoms can migrate in a crystal lattice during solid-state diffusion (e.g., vacancy and interstitial mechanisms), which are influenced by both the mineral lattice and surrounding environment. Interestingly, measured solid-state diffusion coefficients for silicates (and also many oxides and carbonates) are several orders of magnitude higher in the presence of water compared to dry air (Giletti, 1985; Cole and Chakraborty, 2001; Zhang et al., 2006) for high temperature systems. Thus a diffusion coefficient measured at high temperatures under dry conditions may not apply to an aqueous system at ambient temperatures because it may involve a fundamentally different mechanism or multiple mechanisms conflated into one.

We raise these points in order to emphasize the possibility that diffusion coefficients at low temperatures may be larger than would be expected from extrapolating high temperature data, due possibly to a change in diffusion mechanism and/or the material under investigation. Consequently, one cannot rule out solid-state diffusion as a mechanism of stable mineral recrystallization based solely on reported diffusion coefficients. Clearly, resolving this issue as well as identifying the driving force of stable mineral recrystallization must be done in the future to move the field forward.

\section{OUTLOOK}

Experimental observations of stable mineral recrystallization have generated fascinating findings and questions. The collective result that small particles (i.e., $\mathrm{nm}$ to $\mu \mathrm{m}$ scale) can undergo rapid and extensive stable mineral recrystallization in the presence of a saturated solution indicates that minerals can be chemically dynamic at chemical equilibrium in low temperature aqueous environments. Such experimental findings are especially significant given the suggestion that stable mineral recrystallization operates in natural systems over geological time scales, which can alter the isotopic and elemental compositions of minerals in sediments and rocks, as well as the fate of toxic elements in contaminated environments. Determining the relative importance of stable mineral recrystallization compared to other geochemical processes is still, however, difficult due to critical knowledge gaps regarding when and how it occurs. 
Below, we outline the main issues that should be addressed to advance this field and the ability to account for the occurrence of stable mineral recrystallization in natural systems.

Perhaps the most important step towards understanding the importance of stable mineral recrystallization in nature is the development of analytical capabilities to quantify exchange rates accurately in the laboratory. Quantifying recrystallization rates and extents from laboratory observations requires a critical assumption regarding the spatial distribution of isotopes and elements in a mineral. As discussed in detail in this contribution, this assumption can lead to very different calculated rates and extents and, hence, conclusions regarding the fraction of the mineral that has recrystallized at a given point in time. One reason that these assumptions have been difficult to test is that they require the ability to resolve isotopic and elemental compositions in a mineral at fine spatial scales, which is technically challenging.

We believe that this issue can be addressed in the future using two approaches. First, techniques like nanoscale secondary ion mass spectrometry (nano-SIMS) can be employed to measure isotopic and elemental compositions at the necessary spatial scales, provided that the mineral specimen is sufficiently large. Second, though not providing molecular-scale information, experiments in which the solid:fluid mass ratios are systematically varied may be used as indirect means to test the assumptions used in the homogenous and heterogeneous models, as this ratio affects each model uniquely.

Accounting for stable mineral recrystallization in natural systems also requires an understanding of the thermodynamic driving force(s) and molecular-scale mechanism of stable mineral recrystallization. The thermodynamic driving force may be elucidated using thorough spectroscopic and microscopic analyses to determine if minerals do indeed change in subtle, but not overt, ways as a result of stable mineral recrystallization. The molecular-scale mechanism (i.e., solid-state diffusion vs. dissolution and precipitation) may be elucidated using nano-SIMS to map the spatial distribution of isotopes and elements (e.g., Bowman et al., 2008). In minerals in which dissolution-precipitation dominates, distinct and abrupt boundaries in isotopic compositions are expected between the initial and recrystallized solids, if the recrystallized solid is added at the spatial scale resolvable by the technique. If solid-state diffusion dominates, the expected observation would be a continuous gradient across the solid. 
Establishing the importance of experimental conditions on recrystallization rates is critical for translating laboratory observations to natural systems. Because redox-inactive recrystallization rates in the lab tend to decline rapidly, the obvious question arises: are the minerals used in the laboratory appropriate analogs for natural mineral specimens? Prior work has observed that natural calcite specimens recrystallize at slower rates than synthetic specimens (Mozeto et al., 1984), but there is insufficient data to generalize this finding. Consequently, there is a need for characterize exchange systematics in a wide range of minerals having different origins, chemistries, and morphological characteristics.

More work will also be needed to assess when stable mineral recrystallization occurs in natural systems and if measurements of environmental samples are consistent with stable mineral recrystallization. A promising step in this direction is a recent study by Tishchenko et al. (2015), who amended a tropical soil with isotopically labeled aqueous $\mathrm{Fe}^{2+}$ under anaerobic conditions and monitored changes in the iron isotopic composition of different extractable pools in the soil over time. The authors observed significant recrystallization, although mineral transformation processes other than stable mineral recrystallization likely occurred. While such studies generate data that is far more difficult to interpret than data produced in closed laboratory systems, the information provided is critically important for testing hypotheses developed in laboratory experiments.

Addressing these knowledge gaps will improve interpretations of mineral isotopic and elemental compositions in the rock record and the use of minerals to remediate environmental contamination. If stable mineral recrystallization occurs extensively in natural systems, it has important implication for the use of mineral-based remediation in environments contaminated with toxic elements by constraining the extent and rate of recrystallization. Stable mineral recrystallization also has profound implications for proxy-based reconstructions of the past. Site-specific differences that are post-depositional in nature can cause misinterpretations of the state of the system in the past, which can lead to imprecise interpretations at the global scale. Of course, proxy-based reconstructions have been validated for many systems, suggesting that in many cases elemental and isotopic compositions of minerals are generally preserved over geological time scales, and hence that stable mineral recrystallization may only impact proxy 
records under certain conditions and when considering certain trace constituents. Identifying those conditions and constituents susceptible to alteration, in addition to understanding the mechanisms of stable mineral recrystallization, is critical to defining the utility of a given proxy, selecting the appropriate archive and tools, and (ultimately) improving the accuracy of our interpretations of the past.

\section{ACKNOWLEDGEMENTS}

This work was supported by U.S. National Science Foundation Grants EAR-1451593 and EAR-OCE-1154839. The authors thank E. Curti and R. Handler for generously providing original datasets from their studies, and E. Curti, P. Joshi, and M. Scherer for providing feedback and conversations during the writing of this manuscript. The authors also thank two anonymous reviewers, Andrew Frierdich, and associate editor Jeffery Catalano for constructive comments that greatly helped to revise the original manuscript. This research uses data provided by the Ocean Drilling Program (ODP).

Anand P., Elderfield H. and Conte M.H. (2003) Calibration of Mg/Ca thermometry in planktonic foraminifera from a sediment trap time series. Paleoceanography 18, 1-15.

Avrahamov N., Sivan O., Yechieli Y. and Lazar B. (2013) Carbon isotope exchange during calcite interaction with brine: Implications for $14 \mathrm{C}$ dating of hypersaline groundwater. Radiocarbon 55.

Baker P.A., Gieskes J.M. and Elderfield H. (1982) Diagenesis of carbonates in deep-sea sediments - Evidence from $\mathrm{Sr} / \mathrm{Ca}$ ratios and interstitial dissolved $\mathrm{Sr}^{2+}$ data. Journal of Sedimentary Petrology 52, 71-82.

Bathurst R.G. (1975) Carbonate sediments and their diagenesis, 2 ed. Elsevier Scientific Pub. Co., Amsterdam New York.

Beard B.L., Handler R.M., Scherer M.M., Wu L., Czaja A.D., Heimann A. and Johnson C.M. (2010) Iron isotope fractionation between aqueous ferrous iron and goethite. Earth Planet. Sci. Lett. 295, 241-250. 
Berner R.A. (1975) The role of magnesium in the crystal growth of calcite and aragonite from sea water. Geochim. Cosmochim. Acta 39, 489-504.

Bischoff J.L. and Fyfe W.S. (1968) Catalysis, inhibition, and the calcite-aragonite problem; [Part] 1, The aragonite-calcite transformation. Am. J. Sci. 266, 65-79.

Bosbach D., Melanie B. and Volker M. (2010) Experimental study on $\mathrm{Ra}^{2+}$ uptake by barite $\left(\mathrm{BaSO}_{4}\right)$ - Kinetics of solid solution formation via $\mathrm{BaSO}_{4}$ dissolution and $\mathrm{Ra}_{\times} \mathrm{Ba}_{1-\mathrm{x}} \mathrm{SO}_{4}$ (re)precipitation. Swedish Nuclear Fuel and Waste Management Co (Svensk Kärnbränslehantering AB).

Bowman J.R., Valley J.W. and Kita N.T. (2008) Mechanisms of oxygen isotopic exchange and isotopic evolution of ${ }^{18} \mathrm{O} /{ }^{16} \mathrm{O}$-depleted periclase zone marbles in the Alta aureole, Utah: insights from ion microprobe analysis of calcite. 157, 77-93.

Brandt F., Curti E., Klinkenberg M., Rozov K. and Bosbach D. (2015) Replacement of barite by a $(\mathrm{Ba}, \mathrm{Ra}) \mathrm{SO}_{4}$ solid solution at close-to-equilibrium conditions: A combined experimental and theoretical study. Geochim. Cosmochim. Acta 155, 1-15.

Budd D.A. (1988) Aragonite-to-calcite transformation during fresh-water diagenesis of carbonates: Insights from pore-water chemistry. Geological Society of America Bulletin 100, 1260-1270.

Carlsson T. and Aalto H. (1997) Coprecipitation of Ni with calcite: An experimental study. MRS Proceedings 506, 621.

Cheng L., Lyman P.F., Sturchio N.C. and Bedzyk M.J. (1997) X-ray standing wave investigation of the surface structure of selenite anions adsorbed on calcite. Surf. Sci. 382, L690-L695.

Cole D.R. and Chakraborty S. (2001) Rates and mechanisms of isotopic exchange. Rev. Mineral. Geochem. 43, 83-223.

Cooper D.C., Neal A.L., Kukkadapu R.K., Brewe D., Coby A. and Picardal F.W. (2005) Effects of sediment iron mineral composition on microbially mediated changes in divalent metal speciation: Importance of ferrihydrite. Geochim. Cosmochim. Acta 69, 1739-1754.

Cooper D.C., Picardal F., Rivera J. and Talbot C. (2000) Zinc Immobilization and Magnetite Formation via Ferric Oxide Reduction by Shewanella putrefaciens 200. Environ. Sci. Technol. 34, 100-106.

Coughlin B.R. and Stone A.T. (1995) Nonreversible adsorption of divalent metal-ions (Mn"II, CoII $\mathrm{Ni}^{\mathrm{II}} \mathrm{Cu}^{\mathrm{II}}$ and $\mathrm{Pb}^{\mathrm{II}}$ ) onto goethite - Effects of acidification, Fe ${ }^{\mathrm{II}}$ addition, and picolinic-acid addition. Environ. Sci. Technol. 29, 2445-2455. 
Criss R.E., Gregory R.T. and Taylor H.P. (1987) Kinetic-Theory of Oxygen Isotopic Exchange Between Minerals and Water. Geochim. Cosmochim. Acta 51, 1099-1108.

Crosby H.A., Johnson C.M., Roden E.E. and Beard B.L. (2005) Coupled Fe(II)-Fe(III) Electron and Atom Exchange as a Mechanism for Fe Isotope Fractionation during Dissimilatory Iron Oxide Reduction. Environ. Sci. Technol. 39, 6698-6704.

Curti E., Fujiwara K., Iijima K., Tits J., Cuesta C., Kitamura A., Glaus M.A. and Müller W. (2010) Radium uptake during barite recrystallization at $23 \pm 2{ }^{\circ} \mathrm{C}$ as a function of solution composition: An experimental ${ }^{133} \mathrm{Ba}$ and ${ }^{226} \mathrm{Ra}$ tracer study. Geochim. Cosmochim. Acta 74, 3553-3570.

Curti E., Kulik D.A. and Tits J. (2005) Solid solutions of trace Eu(III) in calcite: Thermodynamic evaluation of experimental data over a wide range of $\mathrm{pH}$ and $\mathrm{pCO}_{2}$. Geochim. Cosmochim. Acta 69, 1721-1737.

Cygan R.T., Wright K., Fisler D.K., Gale J.D. and Slater B. (2002) Atomistic models of carbonate minerals: Bulk and surface structures, defects, and diffusion. Mol. Simul. 28, 475-495.

Das H.A., Van Der Weyden R.D. and Vanderweyden R.D. (1995) Isotopic exchange measurements in batch adsorption and desorption experiments. J. Radioanal. Nucl. Chem. $191,229-238$.

Davis J.A., Fuller C.C. and Cook A.D. (1987) A Model for trace-metal sorption processes at the calcite surface - Adsorption of $\mathrm{Cd}^{2+}$ and subsequent solid-solution formation. Geochim. Cosmochim. Acta 51, 1477-1490.

Dekens P.S., Lea D.W., Pak D.K. and Spero H.J. (2002) Core top calibration of Mg/Ca in tropical foraminifera: Refining paleotemperature estimation. Geochemistry, Geophysics, Geosystems 3, 1-29.

Delaney M.L. (1989) Temporal changes in interstitial water chemistry and calcite recrystallization in marine sediments. Earth Planet. Sci. Lett. 95, 23-37.

Doerner H.A. and Hoskins W.M. (1925) Co-precipitation of radium and barium sulfates. J. Am. Chem. Soc. 47, 662-675.

Dubinina E.O. and Lakshtanov L.Z. (1997) A kinetic model of isotopic exchange in dissolutionprecipitation processes. Geochim. Cosmochim. Acta 61, 2265-2273.

Duffield R.B. and Calvin M. (1946) The Stability of Chelate Compounds. III. Exchange Reactions of Copper Chelate Compounds. J. Am. Chem. Soc. 68, 557-561. 
Echigo T., Aruguete D.M., Murayama M. and Hochella Jr M.F. (2012) Influence of size, morphology, surface structure, and aggregation state on reductive dissolution of hematite nanoparticles with ascorbic acid. Geochim. Cosmochim. Acta 90, 149-162.

Echigo T., Monsegue N., Aruguete D.M., Murayama M. and Hochella M.F. (2013) Nanopores in hematite $\left(\alpha-\mathrm{Fe}_{2} \mathrm{O}_{3}\right)$ nanocrystals observed by electron tomography. Am. Mineral. 98, 154162.

Edgar K.M., Pälike H. and Wilson P.A. (2013) Testing the impact of diagenesis on the $\delta 18 \mathrm{O}$ and 813C of benthic foraminiferal calcite from a sediment burial depth transect in the equatorial Pacific. Paleoceanography 28, 468-480.

Eggins S., De Deckker P. and Marshall J. (2003) Mg/Ca variation in planktonic foraminifera tests: implications for reconstructing palaeo-seawater temperature and habitat migration. Earth Planet. Sci. Lett. 212, 291-306.

Eggins S.M., Sadekov A. and De Deckker P. (2004) Modulation and daily banding of Mg/Ca in Orbulina universa tests by symbiont photosynthesis and respiration: a complication for seawater thermometry? Earth Planet. Sci. Lett. 225, 411-419.

Elzinga E.J. (2016) ${ }^{54} \mathrm{Mn}$ Radiotracers Demonstrate Continuous Dissolution and Reprecipitation of Vernadite $\left(\delta-\mathrm{MnO}_{2}\right)$ during Interaction with Aqueous $\mathrm{Mn}(\mathrm{II})$. Environ. Sci. Technol. 50, 8670-8677.

Elzinga E.J. and Kustka A.B. (2015) A Mn-54 radiotracer study of Mn isotope solid-liquid exchange during reductive transformation of vernadite $\left(\delta-\mathrm{MnO}_{2}\right)$ by aqueous $\mathrm{Mn}(\mathrm{II})$. Environ. Sci. Technol. 49, 4310-4316.

Elzinga E.J., Rouff A.A. and Reeder R.J. (2006) The long-term fate of $\mathrm{Cu}^{2+}, \mathrm{Zn}^{2+}$, and $\mathrm{Pb}^{2+}$ adsorption complexes at the calcite surface: An X-ray absorption spectroscopy study. Geochim. Cosmochim. Acta 70, 2715-2725.

Epstein S., Buchsbaum R., Lowenstam H. and Urey H.C. (1951) Carbonate-water isotopic temperature scale. Geological Society of America Bulletin 62, 417-426.

Fantle M.S. (2010) Evaluating the Ca isotope proxy. Am. J. Sci. 310, 194-230.

Fantle M.S. (2015) Calcium isotopic evidence for rapid recrystallization of bulk marine carbonates and implications for geochemical proxies. Geochim. Cosmochim. Acta 148, 378401.

Fantle M.S. and DePaolo D.J. (2006) Sr isotopes and pore fluid chemistry in carbonate sediment of the Ontong Java Plateau: Calcite recrystallization rates and evidence for a rapid rise in seawater Mg over the last 10 million years. Geochim. Cosmochim. Acta 70, 3883-3904. 
Fantle M.S. and DePaolo D.J. (2007) Ca isotopes in carbonate sediment and pore fluid from ODP Site 807A: The $\mathrm{Ca}^{2+}{ }_{(\mathrm{aq})}$-calcite equilibrium fractionation factor and calcite recrystallization rates in Pleistocene sediments. Geochim. Cosmochim. Acta 71, 2524-2546.

Fantle M.S. and Higgins J. (2014) The effects of diagenesis and dolomitization on Ca and Mg isotopes in marine platform carbonates: Implications for the geochemical cycles of $\mathrm{Ca}$ and Mg. Geochim. Cosmochim. Acta 142, 458-481.

Fantle M.S., Maher K.M. and DePaolo D.J. (2010) Isotopic approaches for quantifying the rates of marine burial diagenesis. Reviews of Geophysics 48, RG3002.

Fisler D.K. and Cygan R.T. (1999) Diffusion of Ca and Mg in calcite. Am. Mineral. 84, 1392-1399.

Folk R.L. (1965) Some aspects of recrystallization in ancient limestones, in: Pray, L.C., Murray, R.C. (Eds.), Dolomitization and Limestone Diagenesis: A Symposium. Society of Economic Paleontologists and Mineralogists, Special publication., pp. 14-48.

Frierdich A.J., Beard B.L., Reddy T.R., Scherer M.M. and Johnson C.M. (2014a) Iron isotope fractionation between aqueous $\mathrm{Fe}(\mathrm{II})$ and goethite revisited: New insights based on a multi-direction approach to equilibrium and isotopic exchange rate modification. Geochim. Cosmochim. Acta 139, 383-398.

Frierdich A.J., Beard B.L., Rosso K.M., Scherer M.M., Spicuzza M.J., Valley J.W. and Johnson C.M. (2015a) Low temperature, non-stoichiometric oxygen-isotope exchange coupled to $\mathrm{Fe}(\mathrm{II})$-goethite interactions. Geochim. Cosmochim. Acta 160, 38-54.

Frierdich A.J., Beard B.L., Scherer M.M. and Johnson C.M. (2014b) Determination of the Fe(II)aqmagnetite equilibrium iron isotope fractionation factor using the three-isotope method and a multi-direction approach to equilibrium. Earth Planet. Sci. Lett. 391, 77-86.

Frierdich A.J. and Catalano J.G. (2012a) Controls on Fe(II)-Activated Trace Element Release from Goethite and Hematite. Environ. Sci. Technol. 46, 1519-1526.

Frierdich A.J. and Catalano J.G. (2012b) Fe(II)-Mediated Reduction and Repartitioning of Structurally Incorporated $\mathrm{Cu}, \mathrm{Co}$, and $\mathrm{Mn}$ in Iron Oxides. Environ. Sci. Technol. 46, 1107011077.

Frierdich A.J., Helgeson M., Liu C., Wang C., Rosso K.M. and Scherer M.M. (2015b) Iron Atom Exchange between Hematite and Aqueous Fe(II). Environ. Sci. Technol. 49, 8479-8486.

Frierdich A.J., Luo Y. and Catalano J.G. (2011) Trace element cycling through iron oxide minerals during redox-driven dynamic recrystallization. Geology 39, 1083-1086. 
Frierdich A.J., Scherer M.M., Bachman J.E., Engelhard M.H., Rapponotti B.W. and Catalano J.G. (2012) Inhibition of trace element release during Fe(II)-activated recrystallization of Al-, Cr-, and Sn-substituted goethite and hematite. Environ. Sci. Technol., 10031-10039.

Frierdich A.J., Spicuzza M.J. and Scherer M.M. (2016) Oxygen Isotope Evidence for Mn(II)Catalyzed Recrystallization of Manganite ( $\gamma-\mathrm{MnOOH})$. Environ. Sci. Technol. 50, 63746380 .

Fyfe W.S. and Bischoff J.L. (1965) The calcite-aragonite problem, in: Pray, L.C., Murray, R.C. (Eds.), Dolomitization and limestone diagenesis; a symposium. Society of Economic Paleontologists and Mineralogists., Tulsa, OK, pp. 3-13.

Gallagher K.J., Feitknecht W. and Mannweiler U. (1968) Mechanism of Oxidation of Magnetite to $\gamma-\mathrm{Fe}_{2} \mathrm{O}_{3}$. Nature 217, 1118-1121.

Giletti B.J. (1985) The nature of oxygen transport within minerals in the presence of hydrothermal water and the role of diffusion. Chem. Geol. 53, 197-206.

Gonfiantini R. and Zuppi G.M. (2003) Carbon isotope exchange rate of DIC in karst groundwater. Chem. Geol. 197, 319-336.

Gorski C.A., Handler R.M., Beard B.L., Pasakarnis T., Johnson C.M. and Scherer M.M. (2012) Fe Atom Exchange between Aqueous $\mathrm{Fe}^{2+}$ and Magnetite. Environ. Sci. Technol. 46, 1239912407.

Gorski C.A. and Scherer M.M. (2011) $\mathrm{Fe}^{2+}$ Sorption at the Fe Oxide-Water Interface: A Revised Conceptual Framework, in: Tratnyek, P.G., Grundl, T.J., Haderlein, S.B. (Eds.), Aquatic Redox Chemistry. American Chemical Society, Washington, pp. 315-343.

Guilbaud R., Butler I.B., Ellam R.M., Rickard D. and Oldroyd A. (2011) Experimental determination of the equilibrium $\mathrm{Fe}$ isotope fractionation between $\mathrm{Fe}^{2+}{ }_{\mathrm{aq}}$ and $\mathrm{FeS}_{\mathrm{m}}$ (mackinawite) at 25 and $2{ }^{\circ} \mathrm{C}$. Geochim. Cosmochim. Acta 75, 2721-2734.

Handler R.M., Beard B.L., Johnson C.M. and Scherer M.M. (2009) Atom Exchange between Aqueous Fe(II) and Goethite: An Fe Isotope Tracer Study. Environ. Sci. Technol. 43, 11021107.

Handler R.M., Frierdich A.J., Johnson C.M., Rosso K.M., Beard B.L., Wang C., Latta D.E., Neumann A., Pasakarnis T., Premaratne W.A.P.J. and Scherer M.M. (2014) Fe(II)Catalyzed Recrystallization of Goethite Revisited. Environ. Sci. Technol. 48, 11302-11311.

Heberling F., Bosbach D., Eckhardt J.-D., Fischer U., Glowacky J., Haist M., Kramar U., Loos S., Müller H.S., Neumann T., Pust C., Schäfer T., Stelling J., Ukrainczyk M., Vinograd V., Vučak M. and Winkler B. (2014) Reactivity of the calcite-water-interface, from molecular scale processes to geochemical engineering. Appl. Geochem. 45, 158-190. 
Heberling F., Denecke M.A. and Bosbach D. (2008) Neptunium(V) coprecipitation with calcite. Environ. Sci. Technol. 42, 471-476.

Hinkle M.A.G. and Catalano J.G. (2015) Effect of phosphate and sulfate on Ni repartitioning during Fe(II)-catalyzed Fe(III) oxide mineral recrystallization. Geochim. Cosmochim. Acta $165,62-74$.

Inks C.G. and Hahn R.B. (1967) Determination of Surface Area of Calcium Carbonate by Isotopic Exchange. Anal. Chem. 39, 625-628.

Jenne E.A. (1968) Controls on $\mathrm{Mn}, \mathrm{Fe}, \mathrm{Co}, \mathrm{Ni}, \mathrm{Cu}$, and $\mathrm{Zn}$ concentrations in soils and water Significant role of hydrous Mn and Fe oxides, Trace Inorganics In Water, pp. 337-387.

Jones A.M., Collins R.N., Rose J. and Waite T.D. (2009) The effect of silica and natural organic matter on the $\mathrm{Fe}(\mathrm{II})$-catalysed transformation and reactivity of $\mathrm{Fe}(\mathrm{III})$ minerals. Geochim. Cosmochim. Acta 73, 4409-4422.

Joshi P. and Gorski C.A. (2016) Anisotropic Morphological Changes in Goethite during $\mathrm{Fe}^{2+}$ Catalyzed Recrystallization. Environ. Sci. Technol. 50, 7315-7324.

Killingley J.S. (1983) Effects of diagenetic recrystallization on ${ }^{18} \mathrm{O} /{ }^{16} \mathrm{O}$ values of deep-sea sediments. Nature 301, 594-597.

Klinkenberg M., Brandt F., Breuer U. and Bosbach D. (2014) Uptake of Ra during the recrystallization of barite: A microscopic and time of flight-secondary ion mass spectrometry study. Environ. Sci. Technol. 48, 6620-6627.

Kronenberg A.K., Yund R.A. and Giletti B.J. (1984) Carbon and oxygen diffusion in calcite Effects of Mn content and $\mathrm{pH}_{2} \mathrm{O}$. Phys. Chem. Miner. 11, 101-112.

Lahav N. and Bolt G.H. (1964) Self-diffusion of Ca45 onto certain carbonates. Soil Sci. 97, 293299.

Latta D.E., Bachman J.E. and Scherer M.M. (2012a) Fe electron transfer and atom exchange in goethite: Influence of Al-substitution and anion sorption. Environ. Sci. Technol. 46, 1061410623.

Latta D.E., Gorski C.A. and Scherer M.M. (2012b) Influence of $\mathrm{Fe}^{2+}$-catalysed iron oxide recrystallization on metal cycling. Biochem. Soc. Trans. 40, 1191-1197.

Lestini L., Beaucaire C., Vercouter T. and Descostes M. (2013) Radium uptake by recrystallized gypsum: an incorporation study. Procedia Earth and Planetary Science 7, 479-482.

Maher K., DePaolo D.J. and Lin J.C.F. (2004) Rates of silicate dissolution in deep-sea sediment: In situ measurement using U-234/U-238 of pore fluids. Geochim. Cosmochim. Acta 68, 4629-4648. 
Malone M.J., Baker P.A. and Burns S.J. (1996) Recrystallization of dolomite: An experimental study from 50-200 degrees C. Geochim. Cosmochim. Acta 60, 2189-2207.

Manheim F.T. (1976) Interstitial waters of marine sediments, in: Riley, J.P., Chester, R. (Eds.), Treatise on Chemical Oceanography. Academic Press, New York, pp. 115-186.

Manheim F.T. and Sayles F.L. (1971) Interstitial water studies on small core samples, Leg 8, in: Tracey, J.I., Jr. (Ed.), Initial reports of the Deep Sea Drilling Project. Texas A \& M University, Ocean Drilling Program, College Station, TX, United States, pp. 857-869.

McBride M.B. (1980) Chemisorption of $\mathrm{Cd}^{2+}$ on Calcite Surfaces. Soil Sci. Soc. Am. J. 44, 26-28.

McGregor H.V. and Gagan M.K. (2003) Diagenesis and geochemistry of Porites corals from Papua New Guinea: Implications for paleoclimate reconstruction. Geochim. Cosmochim. Acta 67, 2147-2156.

McKay H.A.C. (1938) Kinetics of Exchange Reactions. Nature 142, 997-998.

McManus J., Berelson W.M., Klinkhammer G.P., Johnson K.S., Coale K.H., Anderson R.F., Kumar N., Burdige D.J., Hammond D.E., Brumsack H.J., McCorkle D.C. and Rushdi A. (1998) Geochemistry of barium in marine sediments: Implications for its use as a paleoproxy. Geochim. Cosmochim. Acta 62, 3453-3473.

Morse J.W., Mucci A. and Millero F.J. (1980) The solubility of calcite and aragonite in seawater of $35 \%$ salinity at $25^{\circ} \mathrm{C}$ and atmospheric pressure. Geochim. Cosmochim. Acta 44, 85-94.

Mozeto A.A., Fritz P. and Reardon E.J. (1984) Experimental-Observations on Carbon Isotope Exchange in Carbonate-Water Systems. Geochim. Cosmochim. Acta 48, 495-504.

Mucci A. (1983) The solubility of calcite and aragonite in seawater at various salinities, temperatures, and one atmosphere total pressure. Am. J. Sci. 283, 780-799.

Murray J. and Irvine R. (1893) On the chemical changes which take place in the composition of seawater associated with blue muds on the floor of the ocean. Transactions of the Royal Society of Edinburgh 37, 481-508.

Nakamura M., Yurimoto H. and Watson E.B. (2005) Grain growth control of isotope exchange between rocks and fluids. Geology 33, 829-832.

Navrotsky A., Mazeina L. and Majzlan J. (2008) Size-Driven Structural and Thermodynamic Complexity in Iron Oxides. Science 319, 1635-1638.

Neumann A., Wu L., Li W., Beard B.L., Johnson C.M., Rosso K.M., Frierdich A.J. and Scherer M.M. (2015) Atom exchange between aqueous Fe(II) and structural Fe in clay minerals. Environ. Sci. Technol. 49, 2786-2795. 
Nordstrom D.K., Plummer L.N., Langmuir D., Busenberg E., May H.M., Jones B.F. and Parkhurst D.L. (1990) Revised Chemical Equilibrium Data for Major Water-Mineral Reactions and Their Limitations, Chemical Modeling of Aqueous Systems II. American Chemical Society, pp. 398-413.

Norris T.H. (1950) The The Kinetics of Isotopic Exchange Reactions. The Journal of Physical and Colloid Chemistry 54, 777-783.

Pasakarnis T., McCormick M.L., Parkin G.F., Thompson A. and Scherer M.M. (2015) Fe ${ }^{{ }^{I I}}{ }-$ $\mathrm{Fe}^{\mathrm{III}}$ oxide electron transfer and Fe exchange: Effect of organic carbon. Environ. Chem. 12, 5263.

Pedersen H.D., Postma D., Jakobsen R. and Larsen O. (2005) Fast transformation of iron oxyhydroxides by the catalytic action of aqueous Fe(II). Geochim. Cosmochim. Acta 69, 3967-3977.

Plummer L.N. and Busenberg E. (1982) The solubilities of calcite, aragonite and vaterite in $\mathrm{CO}_{2}-$ $\mathrm{H}_{2} \mathrm{O}$ solutions between 0 and $90^{\circ} \mathrm{C}$, and an evaluation of the aqueous model for the system $\mathrm{CaCO}_{3}-\mathrm{CO}_{2}-\mathrm{H}_{2} \mathrm{O}$. Geochim. Cosmochim. Acta 46, 1011-1040.

Poulson R.L. (2005) Iron isotope exchange kinetics at the nanoparticulate ferrihydrite surface. Am. Mineral. 90, 758-763.

Prieto M. (2009) Thermodynamics of Solid Solution-Aqueous Solution Systems. Rev. Mineral. Geochem. 70, 47-85.

Prieto M., Astilleros J.M. and Fernandez-Diaz L. (2013) Environmental remediation by crystallization of solid solutions. Elements 9, 195-201.

Putnis A. (2009) Mineral Replacement Reactions. Thermodynamics and Kinetics of Water-Rock Interaction 70, 87-124.

Putnis A. (2014) Why mineral interfaces matter. Science 343, 1441-1442.

Putnis A. and John T. (2010) Replacement Processes in the Earth's Crust. Elements 6, 159-164.

Putnis C.V. and Ruiz-Agudo E. (2013) The Mineral-Water Interface: Where Minerals React with the Environment. Elements 9, 177-182.

Rea B.A., Davis J.A. and Waychunas G.A. (1994) Studies of the Reactivity of the Ferrihydrite Surface by Iron Isotopic Exchange and Mossbauer-Spectroscopy. Clays Clay Miner. 42, 23-34.

Reddy T.R., Frierdich A.J., Beard B.L. and Johnson C.M. (2015) The effect of pH on stable iron isotope exchange and fractionation between aqueous Fe(II) and goethite. Chem. Geol. 397, $118-127$. 
Reeder R.J., Elzinga E.J., Tait C.D., Rector K.D., Donohoe R.J. and Morris D.E. (2004) Site-specific incorporation of uranyl carbonate species at the calcite surface. Geochim. Cosmochim. Acta 68, 4799-4808.

Reeves D. and Rothman D.H. (2013) Age dependence of mineral dissolution and precipitation rates. Global Biogeochem. Cycles 27, 906-919.

Richter F.M. (1996) Models for the coupled Sr-sulfate budget in deep-sea carbonates. Earth Planet. Sci. Lett. 141, 199-211.

Richter F.M. and DePaolo D.J. (1987) Numerical models for diagenesis and the Neogene Sr isotopic evolution of seawater from DSDP Site 590B. Earth Planet. Sci. Lett. 83, 27-38.

Richter F.M. and DePaolo D.J. (1988) diagenesis and sr isotopic evolution of seawater using data from DSDP-590B and DSDP-575. Earth Planet. Sci. Lett. 90, 382-394.

Richter F.M. and Liang Y. (1993) The rate and consequences of Sr diagenesis in deep-sea carbonates. Earth Planet. Sci. Lett. 117, 553-565.

Rosso K.M., Yanina S.V., Gorski C.A., Larese-Casanova P. and Scherer M.M. (2010) Connecting observations of hematite $\left(\alpha-\mathrm{Fe}_{2} \mathrm{O}_{3}\right)$ growth catalyzed by $\mathrm{Fe}(\mathrm{II})$. Environ. Sci. Technol. 44, 61-67.

Rudnicki M.D., Wilson P.A. and Anderson W.T. (2001) Numerical models of diagenesis, sediment properties, and pore fluid chemistry on a paleoceanographic transect: Blake Nose, Ocean Drilling Program Leg 171B. Paleoceanography 16, 563-575.

Sadekov A.Y., Eggins S.M. and De Deckker P. (2005) Characterization of Mg/Ca distributions in planktonic foraminifera species by electron microprobe mapping. Geochemistry, Geophysics, Geosystems 6, n/a-n/a.

Sayles F.L. (1979) Composition and diagenesis of interstitial solutions .1. Fluxes across the seawater-sediment interface in the atlantic ocean. Geochim. Cosmochim. Acta 43, 527-545.

Sayles F.L. (1981) The composition and diagenesis of interstitial solutions .2. Fluxes and diagenesis at the water-sediment interface in the high-latitude north and south-atlantic. Geochim. Cosmochim. Acta 45, 1061-1086.

Sayles F.L. and Manheim F.T. (1975) Interstitial solutions and diagenesis in deeply buried marine sediments: results from the Deep Sea Drilling Project. Geochim. Cosmochim. Acta 39, 103-127.

Schrag D.P., DePaolo D.J. and Richter F.M. (1992) Oxygen isotope exchange in a two-layer model of oceanic crust. Earth Planet. Sci. Lett. 111, 305-317. 
Schrag D.P., DePaolo D.J. and Richter F.M. (1995) Reconstructing past sea surface temperatures: Correcting for diagenesis of bulk marine carbonate. Geochim. Cosmochim. Acta 59, 22652278.

Sexton P.F., Wilson P.A. and Pearson P.N. (2006) Microstructural and geochemical perspectives on planktic foraminiferal preservation: "Glassy" versus "Frosty". Geochem. Geophys. Geosyst. 7, 29.

Sidhu P.S., Gilkes R.J. and Posner A.M. (1977) Mechanism of low-temperature oxidation of synthetic magnetites. Journal of Inorganic \& Nuclear Chemistry 39, 1953-1958.

Silvester E., Charlet L., Tournassat C., Gehin A., Greneche J.M. and Liger E. (2005) Redox potential measurements and Mossbauer spectrometry of $\mathrm{Fe}^{\mathrm{II}}$ adsorbed onto $\mathrm{Fe}^{\mathrm{III}}$ (oxyhydr)oxides. Geochim. Cosmochim. Acta 69, 4801-4815.

Sorby H.C. (1880) Anniversary address of the President (Structure and origin on limestones). Proceedings of the Geological Society of London 36, 46-92.

Spivack A.J. and Edmond J.M. (1987) Boron isotope exchange between seawater and the oceanic crust. Geochim. Cosmochim. Acta 51, 1033-1043.

Spry A. (1969) Metamorphic textures. Oxford, New York.

Stipp S.L., Hochella M.F., Parks G.A. and Leckie J.O. (1992) $\mathrm{Cd}^{2+}$ uptake by calcite, solid-state diffusion, and the formation of solid-solution - Interface processes observed with nearsurface sensitive techniques (XPS, LEED, and AES). Geochim. Cosmochim. Acta 56, 19411954.

Stumm W. and Morgan J. (1970) Aquatic Chemistry. Interscience NY.

Tai C.Y. and Chen F.B. (1998) Polymorphism of $\mathrm{CaCO}_{3}$, precipitated in a constant-composition environment. AIChE J. 44, 1790-1798.

Tang J., Myers M., Bosnick K.A. and Brus L.E. (2003) Magnetite $\mathrm{Fe}_{3} \mathrm{O}_{4}$ nanocrystals: Spectroscopic observation of aqueous oxidation kinetics. The Journal of Physical Chemistry B 107, 7501-7506.

Tishchenko V., Meile C., Scherer M.M., Pasakarnis T.S. and Thompson A. (2015) $\mathrm{Fe}^{2+}$ catalyzed iron atom exchange and re-crystallization in a tropical soil. Geochim. Cosmochim. Acta 148, 191-202.

Urey H.C. (1948) Oxygen isotopes in nature and in the laboratory. Science 108, 489-496.

Urey H.C., Lowenstam H.A., Epstein S. and McKinney C.R. (1951) Measurement of paleotemperatures and temperatures of the upper cretaceous of England, Denmark, and the southeastern United-States. Geological Society of America Bulletin 62, 399-416. 
Vinograd V.L., Brandt F., Rozov K., Klinkenberg M., Refson K., Winkler B. and Bosbach D. (2013) Solid-aqueous equilibrium in the $\mathrm{BaSO}_{4}-\mathrm{RaSO}_{4}-\mathrm{H}_{2} \mathrm{O}$ system: First-principles calculations and a thermodynamic assessment. Geochim. Cosmochim. Acta 122, 398-417.

Wang X., Johnson T.M. and Ellis A.S. (2015a) Equilibrium isotopic fractionation and isotopic exchange kinetics between $\mathrm{Cr}(\mathrm{III})$ and $\mathrm{Cr}(\mathrm{VI})$. Geochim. Cosmochim. Acta 153, 72-90.

Wang X., Johnson T.M. and Lundstrom C.C. (2015b) Low temperature equilibrium isotope fractionation and isotope exchange kinetics between $\mathrm{U}(\mathrm{IV})$ and $\mathrm{U}(\mathrm{VI})$. Geochim. Cosmochim. Acta 158, 262-275.

White A.F., Peterson M.L. and Hochella M.F. (1994) Electrochemistry and dissolution kinetics of magnetite and ilmenite. Geochim. Cosmochim. Acta 58, 1859-1875.

Williams A.G.B. and Scherer M.M. (2004) Spectroscopic evidence for Fe(II)-Fe(III) electron transfer at the Fe oxide-water interface. Environ. Sci. Technol. 38, 4782-4790.

Wise S.W. (1973) Calcareous nannofossils from cores recovered during Leg 18, Deep Sea Drilling Project; biostratigraphy and observations of diagenesis, in: Kulm, L.V.D. (Ed.), Initial reports of the Deep Sea Drilling Project. Texas A \& M University, Ocean Drilling Program, College Station, TX, United States, pp. 569-615.

Wu L., Beard B.L., Roden E.E. and Johnson C.M. (2011) Stable iron isotope fractionation between aqueous Fe(II) and hydrous ferric oxide. Environ. Sci. Technol. 45, 1847-1852.

Wu L., Beard B.L., Roden E.E., Kennedy C.B. and Johnson C.M. (2010) Stable Fe isotope fractionations produced by aqueous Fe(II)-hematite surface interactions. Geochim. Cosmochim. Acta 74, 4249-4265.

Wu L., Percak-Dennett E.M., Beard B.L., Roden E.E. and Johnson C.M. (2012) Stable iron isotope fractionation between aqueous Fe(II) and model Archean ocean Fe-Si coprecipitates and implications for iron isotope variations in the ancient rock record. Geochim. Cosmochim. Acta 84, 14-28.

Yanina S.V. and Rosso K.M. (2008) Linked reactivity at mineral-water interfaces through bulk crystal conduction. Science 320, 218-222.

Yardley B.W.D. (2009) The role of water in the evolution of the continental crust. Journal of the Geological Society 166, 585-600.

Yund R.A., Yund R.A., Tullis J. and Tullis J. (1991) Compositional changes of minerals associated with dynamic recrystallization. Contrib. Mineral. Petrol.

Zachara J.M., Cowan C.E. and Resch C.T. (1991) sorption of divalent metals on calcite. Geochim. Cosmochim. Acta 55, 1549-1562. 
Zarzycki P., Kerisit S. and Rosso K.M. (2015a) Molecular Dynamics Study of Fe(II) Adsorption, Electron Exchange, and Mobility at Goethite $(\alpha-\mathrm{FeOOH})$ Surfaces. The Journal of Physical Chemistry C 119, 3111-3123.

Zarzycki P., Smith D.M. and Rosso K.M. (2015b) Proton Dynamics on Goethite Nanoparticles and Coupling to Electron Transport. J. Chem. Theory Comput. 11, 1715-1724.

Zhang X.Y., Cherniak D.J. and Watson E.B. (2006) Oxygen diffusion in titanite: Lattice diffusion and fast-path diffusion in single crystals. Chem. Geol. 235, 105-123. 